\title{
Effect of oxidative breakers on organic matter degradation, contaminant mobility and critical mineral release during shale- fracturing fluid interactions in the Marcellus Shale
}

Shaun Donmoyer

West Virginia University, sjd0035@mix.wvu.edu

Follow this and additional works at: https://researchrepository.wvu.edu/etd

Part of the Geology Commons

\section{Recommended Citation}

Donmoyer, Shaun, "Effect of oxidative breakers on organic matter degradation, contaminant mobility and critical mineral release during shale-fracturing fluid interactions in the Marcellus Shale" (2021). Graduate Theses, Dissertations, and Problem Reports. 8100.

https://researchrepository.wvu.edu/etd/8100

This Thesis is protected by copyright and/or related rights. It has been brought to you by the The Research Repository @ WVU with permission from the rights-holder(s). You are free to use this Thesis in any way that is permitted by the copyright and related rights legislation that applies to your use. For other uses you must obtain permission from the rights-holder(s) directly, unless additional rights are indicated by a Creative Commons license in the record and/ or on the work itself. This Thesis has been accepted for inclusion in WVU Graduate Theses, Dissertations, and Problem Reports collection by an authorized administrator of The Research Repository @ WVU. For more information, please contact researchrepository@mail.wvu.edu. 
Effect of oxidative breakers on organic matter degradation, contaminant mobility and critical mineral release during shale-fracturing fluid interactions in the Marcellus Shale

Shaun Donmoyer

Thesis Submitted to:

The Eberly College of Arts and Sciences

West Virginia University

In partial fulfillment of the requirements for the degree of

Masters of Science

in

Geology

Shikha Sharma, Ph.D., Chair

Vikas Agrawal, Ph.D.

Timothy Carr, Ph.D.

Alexandra Hakala, Ph.D.

Department of Geology and Geography

Morgantown, WV

2021

Keywords: Oxidative Breakers, Hydraulic Fracturing, Critical Minerals, Organic Contamination Copyright 2021 Shaun Donmoyer 


\title{
Abstract \\ Effect of oxidative breakers on organic matter degradation, contaminant mobility and critical mineral release during shale-fracturing fluid interactions in the Marcellus Shale
}

\begin{abstract}
Shaun Donmoyer
Production of oil and gas from organic-rich shale formations has become viable through advancements in multi-stage hydraulic fracturing. The decline of shale gas production after the initial days of fracturing operations coupled with falling oil and gas prices, has pushed industry operators to use new chemical additives as an attempt to increase hydrocarbon production. The implementation of highly reactive fracturing fluids that include strong oxidizing agents, pose as a potential solution to increase well productivity. Strong oxidizing chemicals commonly known in fracturing operations as breakers, are used to improve the viscosity of gel-based fluids after the proppant is transported into fracture zones of the target formation. These oxidizing agents have been observed to degrade the organic matter and unstable constituents of shale formations. However, fluid-rock interactions during this process have not been extensively investigated. The goal of this study was to investigate the fluid-rock interactions between Marcellus Shale and three solutions of oxidizing hydraulic fracturing fluid (HFF) at formation temperature. Three synthetic HFF solutions containing common oxidative breakers, ammonium persulfate, sodium bromate, and sodium hypochlorite were reacted for a 14-day period to mimic the shut-in period when fluid remains in contact with the reservoir rock during a fracturing operation. The chemical analysis focused on observing organic contaminant release, critical mineral mobility, mineralogy, and significant changes in ionic species. Results showed that individual oxidizing breakers controlled the type and amount of volatile organic compounds (VOCs) and semivolatile organic compounds (SVOCs) present in the control and shale reacted effluents. An abundance of halogenated organic compounds was observed in effluents with sodium bromate and sodium hypochlorite, and negligible amounts were associated with ammonium persulfate. Additionally, the transformation of VOCs was observed to occur between control and shale reacted effluents. Organic acids were present in variable amounts in all effluent samples. Results show an enhanced but variable dissolution of shale organic matter and other unstable constituents such as pyrite by each oxidative fluid. This oxidation of shale organic matter and constituents, stimulated the release of critical minerals such as metals and metalloids into solution. Additionally, shifts in major ions and XRD results indicated that carbonate mineral dissolution and barite precipitation occurred in all shale reacted effluents. Similarly, the precipitation of gypsum was observed to occur in samples where sulfate ions were abundant due to enhanced dissolution of pyrite. Halite precipitation occurred in one effluent sample containing sodium hypochlorite breaker. These results suggest that oxidizing agents in HFF may provide a means for enhanced hydrocarbon production through oxidative dissolution. However, the generation and transformation of VOCs, critical mineral release, and secondary mineral dissolution and precipitation should be considered.
\end{abstract}




\section{Acknowledgments:}

I would like to thank Dr. Shikha Sharma for the opportunity to enhance my background as a Geoscientist and for all her guidance through this project. I would also like to thank my committee members Dr. Timothy Carr, Dr. Vikas Agrawal, and Dr. Alexandra Hakala for their support of this research. I would like to give special thanks to Dr. Vikas Agrawal for significantly helping me these past few months of this project, including teaching me all the sampling and laboratory techniques. Finally, I would like to thank all of my friends and the Department of Geology and Geography for providing an excellent support network and atmosphere during my time at West Virginia University. 
Table of Contents

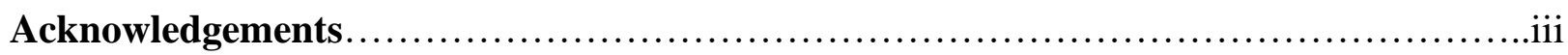

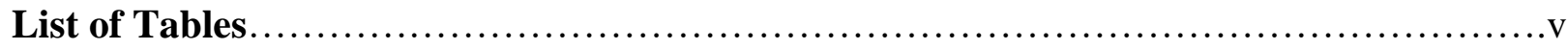

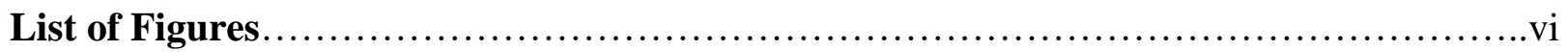

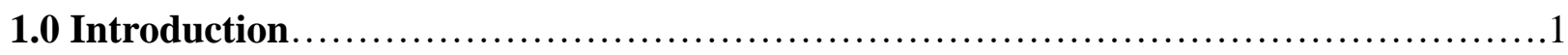

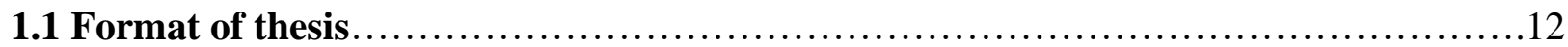

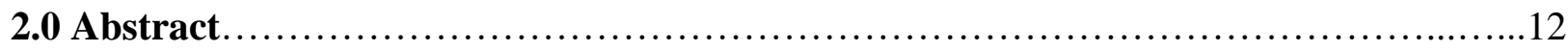

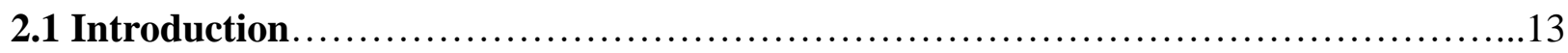

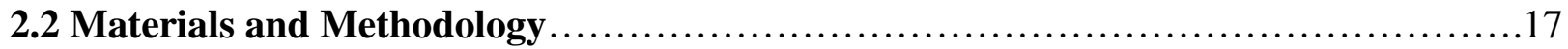

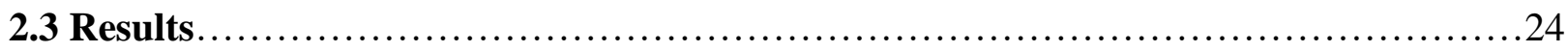

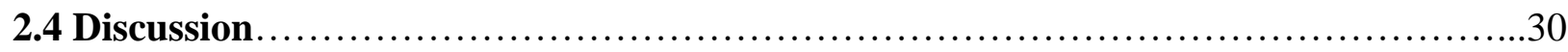

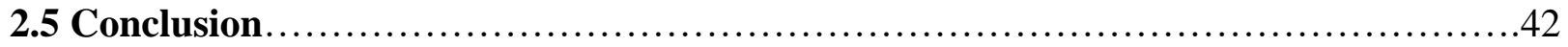

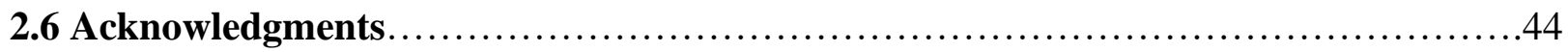

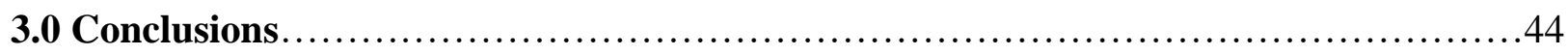

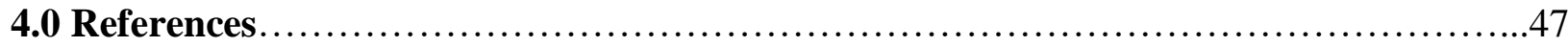

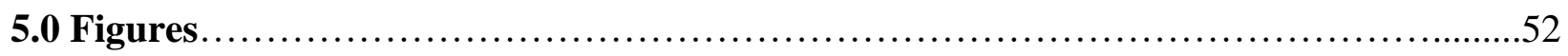

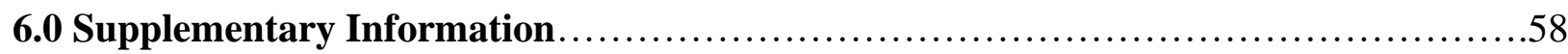




\section{List of Tables}

Table 1: Composition of the synthetic HFF and brine used during reactions. *Denotes the oxidative breaker that was altered between control fluids.

Table 2: Sample abbreviations of control and shale reacted effluents.

Table 3: TOC (\% C) content of the reacted shale samples and NPOC concentrations (mg/l).

Table 4: Organic acid concentrations in control and shale reacted effluents. *ND - Not Detected

Table 5: Quantitative XRD results of the original shale and reacted shale samples. Mineralogical composition is represented by weight percent with quantitative error of $\pm 1 \%$. *ND - Not Detected.

Table 6: Major anion and cation concentrations as measured by IC.

Table S1: Volatile organic compounds observed in the control fluids. Results and MDL are reported in ug/l. *ND - Not Detected

Table S2: Volatile organic compounds observed in shale reacted effluents. Results and MDL are reported in ug/L. *ND - Not Detected

Table S3: Semi volatile organic compounds (PAHs) observed in effluents in this study. Results and MDL are reported in ug/L. *ND - Not Detected

Table S4: Critical minerals (metals and metalloids) measured from ICP-MS and ICP-OES analysis. 


\section{List of Figures}

Figure 1: Heat map summarizing all VOCs observed in effluent samples. Low concentration VOCs are represented by the increasing blue scale and higher concentration VOCs are represented by yellow, orange, and red respectively. Concentrations are reported in ug/L.

Figure 2: Total VOC concentration in shale reacted effluents with respect to the initial ORP of the HFF solution.

Figure 3: Organic acid and NPOC concentrations of control and shale reacted effluents.

Figure 4: Critical mineral concentrations (AMPc and AMP-LM1). Analytes with concentrations $<1 \mathrm{ug} / \mathrm{l}$ were removed (Table S4).

Figure 5: Critical mineral concentrations (SBc and SB-LM1). Analytes with concentrations <1 ug/l were removed (Table S4).

Figure 6: Critical mineral concentrations (SHc and SH-LM1). Analytes with concentrations $<1$ ug/l were removed (Table $\mathbf{S 4}$ ).

Figure 7: Critical mineral concentrations in shale reacted effluents and the initial ORP of HFF before analysis. Notice a higher ORP with higher critical mineral concentrations.

Figure 8: XRD results showing the original mineral composition of LM1 and the composition of LM1 after reaction with the oxidative HFF's. Values were measured within reporting limit standards of $<5 \%$.

Figure 9: Concentrations of barium, sulfate, phosphate, and chloride in control and shale reacted effluents. An increase in sulfate concentration can be associated in samples where $\mathrm{FeS}_{2}$ was consumed to the greatest extent. 


\subsection{Introduction:}

Unconventional shale gas development via hydraulic fracturing has enabled the development of several large shale gas plays resulting in a significant increase in oil and gas production in the United States. Natural gas production from the Marcellus Shale in the Appalachian Basin has made a significant contribution towards meeting the current energy demands of the United States (Brantley et al., 2017, U.S. EIA, 2019). Hydraulic fracturing is the process of inducing fractures into "tight" reservoirs by the injection of fracturing fluids at high pressures to release trapped hydrocarbons into the wellbore. The fluids used during this process are often comprised of $95 \%$ water, $4 \%$ proppant and $1 \%$ additives. Although additives comprise only a tiny percentage of the overall fracturing fluid, volumes reaching 10 million gallons can result in 100,000 gallons of chemical additives (Barati and Liang, 2014). On average, large scale multistage hydraulic fracturing operations require 4.5 million gallons of injected freshwater to stimulate horizontal wells to achieve gas production at the Marcellus Shale's economic level (Kondash et al., 2015, Mohammad-Pajooh et al., 2018). On average roughly $40 \%$ of this fluid returns to the surface upon completion and this fluid has a chemical signature distinctly different from the initially injected HFF (Strong et al., 2014, Hoelzer et al., 2016, Marcon et al., 2017). The chemistry of the produced fluids that return to the surface can be controlled by several parameters such as chemical additives in HFF, formation water, mineralogy, organic matter type and amount during shale-HFF interactions (Ziemkiewicz et al., 2015, Hoelzer et al., 2016, Strong et al., 2014). However, the true impact of these parameters on shale-HFF interactions, especially different chemical additives like oxidative breakers, are not well understood. Due to the large volumes of water used during hydraulic fracturing operations and the copious selection of industry additives, this warrants further investigation of reactions that ensue during hydraulic 
fracturing fluid and formation rock interaction. Understanding these geochemical reactions is essential for understanding contaminant and trace metal release and increasing the efficacy of hydraulic fracturing operations. Knowledge of these reaction mechanisms may help tailor HFF composition specifically to accommodate the geologic factors such as variation in shale mineralogy, organic matter content and type in each well. Using this information, appropriate strategies can be developed to mitigate toxic compounds, improve well productivity, enable proper water re-use and recycling, and sequester critical metals released in produced waters.

\section{Hydraulic fracturing fluid compositions}

Hydraulic fracturing, also known as fracturing, is a hydrocarbon extraction process in which fluids are injected at high pressures into a rock formation to create fracture networks to increase permeability and allowing hydrocarbons to flow into the wellbore. Often, many wells can be placed on a single well pad that all deviate from a singular vertical well (Bazant et al., 2014). The fluids used during these operations are a key component for the successful generation of hydrocarbons from a given well. Hydraulic fracturing fluid is designed to perform various functions over the entirety of an operation. This includes inducing fractures, successfully propping open and maintaining fracture networks and allowing hydrocarbons to flow into the well. In general, hydraulic fracturing fluid is comprised of $95 \%$ fresh water, $4 \%$ proppant and $1 \%$ additives (FracFocus.org). The water used during a hydraulic fracturing operation is usually locally sourced (rivers, lakes, streams etc.) and easily accessible. At times recycled water from a previous fracturing operation is also utilized. The target rock formation that is fractured, often exhibits significant heterogeneity in hydrocarbon content, mineralogy and maturity within a basin. Such heterogeneity is accounted for in the proportion of water, additives and proppant used at a given well (Hoelzer et al., 2016). The additives that are used in the hydraulic fracturing 
fluids serve a multitude of purposes and also control how these injected fluids react with the formation and promote effective hydrocarbon extraction.

The suite of chemical additives in hydraulic fracturing fluid includes an acid to prevent mineral scaling in the wellbore, a gelling agent to transport proppant into the fracture networks, a breaker to control fluid viscosity and a friction reducer to allow immense fluid flow. Guar gum in both the linear and cross-linked varieties is the most common and widespread gelling agent used in the industry (Barati and Liang, 2014). The critical function of the gelling agent is to successfully transport a proppant into the fracture networks. Failure of this process reduces the permeability of the target rock and decreases the hydrocarbon production of a well. Currently, the most used proppant is 20/40 mesh sand which accounts for $\sim 85 \%$ of the industry, However other proppants such as resin-coated sand, intermediate strength proppants, ceramic proppants and high strength proppants such as sintered bauxite and zirconium oxide are used (Economides et al., 1989, Montgomery et al., 2010). Proppant transport and placement are most successful with a highly viscous fluid and are least effective during the a "slickwater" operation. Slickwater fracturing fluids consist mainly of water with low polymer concentrations, primarily as friction reducers. They are implemented where there is concern that a viscous fracturing fluid may cause formation damage in tight unconventional reservoirs (Barati et al., 2009). High-velocity fluid flow is necessary for the successful placement of proppant during a slickwater operation or proppants will settle in the wellbore before reaching the fractures (Dayan et al., 2009). Other additives such as $\mathrm{pH}$ controllers, corrosion inhibitors, biocides, clay stabilizers and petroleum distillates have marginal composition but help to maintain the effectiveness of other additives. Typically, the laterally drilled section of the well is fractured in successional stages to account for extreme lengths of the horizontal leg of the well. Once fractures have been opened and 
propagated in each stage, fracturing fluids remain in contact with the target formation during a shut-in period that can last several days to weeks. After the shut-in phase, breakers are added to destabilize the polymer chains of the gelling agents to reduce viscosity to allow flowback of hydrocarbons from the fractures into the well. This must be accomplished by removing the fluid without moving the proppant pack or damaging the conductivity of the proppant pack (Dayan et al., 2009).

The most commonly used breakers are oxidizing breakers that change the fluid to a less viscous state so it can flow to the well head as flowback or produced water (Barati and Liang, 2014). Over 50\% of operators report the use of an oxidizing breaker in their hydraulic fracturing fluid (Elsner and Hoelzer, 2016). Other common breakers include acids and the use of certain enzymes. In hydraulic fracturing operations that involve a cross-linked borate system, acids are commonly implemented as breakers (Sumner and Plate, 2019). Enzymes from the hemicellulose class such as cellulose, amylase and pectinase have been implemented as breakers during hydraulic fracturing operations (Montgomery, 2013, Barati and Liang, 2014). However, pH and temperature dependencies limit the use and effectiveness of acidic and enzymatic breakers during hydraulic fracturing operations (Barati and Liang, 2014).

The commonly used oxidative breakers function by effectively breaking the backbone and side chains of polymer chains of gelling agents by cleaving acetyl linkages (Montgomery, 2013). Strong oxidizers such as persulfates, form a free radical sulfate ion and oxygen at elevated temperatures that attach to the backbone of polymer and degrade it into its constitutive sugars (Montgomery, 2013). Subsequently, residual sugars may form insoluble precipitates limiting formation conductivity (Montgomery, 2013, Barati and Liang, 2014). Other oxidizers such as peroxides effectively work by the release of oxygen when in solution with water. The 
effectiveness of peroxides as an oxidizer significantly decreases with exposure to elevated temperature (Hull et al., 2019).

The use of highly oxidizing HFF via the addition of oxidizing breakers is becoming popular among drilling companies and researchers. Shale plays that are rich in organic matter, pyrite, and other minerals deposited in a reducing environment (anoxia) are highly susceptible to oxidation by the addition of oxidative fluids (You et al., 2018). Some researchers have observed that oxidative fluids such as hypochlorite and bromine can effectively remove organic matter in clay rocks (Anderson, 1961, Kuila et al., 2014). Additionally, researchers have posed a new prospect of enhanced oil and gas recovery in shale formations by altering pore structures via oxidation dissolution and organic matter degradation (Hull et al., 2019, Chen et al., 2017, You et al., 2017). Furthermore, the degradation of organic matter by oxidative transformation, may enhance the release of bound hydrocarbons in the shale matrix, increasing the productivity of wells. However, the mechanisms that drive these processes along with the consequences associated with oxidative fluids are poorly understood.

\section{Produced waters}

Produced water is the most massive stream generated by conventional and unconventional hydrocarbon exploration (Sharma et al., 2021). Approximately, 1.7-2.3 billion gallons of produced water are generated each day in the United States alone (Clark et al., 2009). The composition of produced waters varies significantly and causes complex environmental and economic concerns relating to waste water disposal, recycling, and treatment. Produced waters of unconventional hydrocarbon extraction techniques are the combination of returning HFF fluids and formation water. Formation water is the portion of produced water that originates within the source rock and its composition is controlled by the original source of water (connate marine vs. 
non-marine) migration of the basinal fluids, the nature and degree of water-mineral-hydrocarbon interactions, water recharge, and processes such as evaporation and ultrafiltration (Sharma et al., 2021). Flowback water, on the other hand, is the portion of produced water generated through oil and gas production. A large part of the produced water volume contains volumes of the initial injection fluid, especially during early production (Gregory et al., 2011). As the composition of injected fluid varies between wells, the composition of produced water is inherently altered (Orem et al., 2014). Heterogeneity exists in the type and composition of injection fluid along with changes in the formation rock and formation water at the basin scale. The variation of these factors makes it difficult to understand the signatures of produced waters. However, many studies suggest that produced waters exhibit signs of mineral precipitation and dissolution, the proliferation of inorganic and organic compounds, organo-metallic complexes and the presence of elevated dissolved inorganic and organic carbon (Sharma et al., 2021, Phan et al., 2020, Welch et al., 2020, Pilewski et al., 2019, Marcon et al., 2017, Harrison et al., 2017, Jew et al., 2017).

Produced waters are often characterized by high salinity, trace elements, metals, radioactive elements and inorganic and organic compounds (Phan et al., 2015, Marcon et al., 2017, Cluff et al., 2014, Sharma et al., 2021, Welch et al., 2020). Organic compounds are of particular concern as certain compounds pose health and environmental hazards. Benzene, toluene, ethylbenzene, and xylene (BTEX) compounds are of particular concern and are currently regulated by the U.S Environmental Protection Agency. Research and published data show that these compounds specifically benzene, have been detected at elevated concentrations from produced waters (Ziemkiewicz and He, 2015). Research also shows a myriad of organic substances in produced water from shale gas operations such as polycyclic aromatic 
hydrocarbons (PAH), heterocyclic compounds, alkyl phenols, aromatic amines, alkyl aromatics benzenes, alkyl biphenyls, long-chain fatty acids and aliphatic hydrocarbons (Orem et al., 2014). Similar studies observed produced and flowback waters from the Marcellus Shale to contain high levels of low molecular weight organic compounds (Zhu et al., 2015). Some researchers suggest that the origin of organic contaminants may be derived from organic additives in HFF or released from organic matter from the formation rock. These chemicals pose environmental and health hazards if disposed or treated improperly. This has resulted in approximately $46 \%$ of produced water being injected into non-commercial and commercial disposal wells (Guerra et al., 2011). The complex array of compounds and immense volumes of produced water generated by unconventional operations has warranted a better understanding of the processes that source inorganic and organic compounds in produced waters. Understanding produced water signatures may aid in developing unique HFF formulas and water treatment recommendations to mitigate risk of environmental contamination and health hazards.

\section{Marcellus Shale}

The Marcellus Shale formation is one of the largest shale gas plays in the United States (Rozell and Reaven, 2012). The Marcellus Shale is considered the most productive gas play in the world and advancements in multi-stage hydraulic fracturing have allowed the United States to significantly increase natural gas and oil production (U.S EIA, 2018). In 2019, the Energy Information Administration estimated natural gas and crude oil reserves in the Marcellus Shale were 139.4 trillion cubic feet (tcf) and 326 million barrels respectively (EIA, 2021). This formation has become one of the largest exploited shale plays in the United States and has enhanced the global energy industry. 
The Marcellus Shale is a relatively thin (+/- 30m), black organic-rich formation that extends $124,000 \mathrm{~km}^{2}$ from New York to West Virginia (Rozell and Reaven, 2012). The Marcellus Shale is characterized as a carbonaceous silty shale with embedded pyrite, carbonate concretions and trace fossils (EIA, 2017). The lithology of this formation varies significantly across the basin but is dominantly comprised of quartz, feldspar, pyrite, calcite, dolomite and gypsum (EIA, 2017). Patterns of thermal maturity in the Marcellus Shale range from $0.5 \%$ Ro to greater than 3.5\% Ro and generally increase in a southeastern direction across the Appalachian Basin. The significant variation in thermal maturity within the Marcellus Shale corresponds to the amount and type of hydrocarbons available within zones of the formation. Thermal maturity characteristics of the Marcellus Shale indicate zones of dry gas, wet gas, and oil across the basin. However, a majority of the producing zones are in the dry gas window (Zagorski et al., 2017). Hotspot areas of significant hydrocarbon potential and production occur approximately southeast of the $1 \%$ Ro equivalent maturity contour in regions of western Pennsylvania, northern West Virginia, eastern Ohio and southern New York (Zagorski et al. 2017).

The Marcellus Shale is composed of type II and type III kerogen sourced from terrestrial and marine inputs (Agrawal et al., 2017). Kerogen, the fraction of organic matter responsible for hydrocarbon production, is crucial within the Marcellus Shale. Kerogen was characterized across a maturity sequence within the Marcellus (Agrawal et al., 2017). Marcellus samples of lower maturity show an aliphatic kerogen structure with a high percentage of liable functional groups, while more mature samples show an aromatic kerogen structure. The structure of kerogen controls the reactivity and adsorption capacity, and for instance, a higher aromatic structure is associated with larger pore structure and larger surface area for adsorption (Song et al., 2018, Agrawal et al., 2018). However, the interaction of kerogen with HFF is still poorly understood. 
Understanding the changes to the chemical and physical properties of kerogen during fluid-rock interaction of a fracking operation may provide important insight to enhanced oil and gas recovery and mobility of trace metals associated with kerogen.

\section{Previous experimental studies}

Several bench top laboratory experimental studies have investigated the complex reactions between the injected fluid and formation rock at reservoir conditions. The mineralogic composition of the shale in the presence of HFF has been shown to regulate $\mathrm{pH}$ and influence inorganic species in produced waters (Pilewski et al., 2019, Marcon et al., 2017, Wilke et al., 2015). Commonly, carbonate minerals provide buffering capacity, and minerals such as pyrite are sources of sulfate ions in solution. Changes in $\mathrm{pH}$ and influx of ions into solution can cause mineral precipitation and dissolution. Several studies have observed the direct dissolution and precipitation of minerals such as calcite, pyrite, barite and gypsum (Pilewski et al., 2019, Harrison et al., 2017, Marcon et al., 2017, Dustin et al., 2018). Iron-bearing mineral precipitates have been observed during fluid-rock interactions mainly by oxidation from HFF (Jew et al., 2018). In addition, carbonate mineral dissolution and barite precipitation were observed through a series of reactions that included acidic and repurposed hydraulic fracturing fluids (Vankeuren et al. 2017). Mineral precipitation and dissolution reactions are important to consider for extending the life and efficacy of unconventional wells. Mineral scaling is a common issue that can degrade well equipment through corrosion and prevent adequate fluid flow.

Recent studies show that at the laboratory scale, fluid-rock interactions produce low molecular weight organic compounds similar to those of produced fluids from field studies (Ziemkiewicz et al., 2015, Pilewski et al., 2019, Marcon et al., 2017). In addition to this observation, a decrease in dissolved organic carbon is often associated with the proliferation of 
volatile organic compounds. The maturity of the source rock is important to consider when determining the source of organic compounds. Pilewski et al 2019, demonstrated that lower maturity shale samples produce higher concentrations of low molecular weight organic compounds than mature and overmature shale samples. This is because lower maturity shales contain higher concentrations of liable organic compounds that can become solubilized into solution during HFF interaction. More mature shale is characterized by organic material of an aromatic structure that presents the opportunity for solubilized organic compounds to become adsorbed, therefore decreasing DOC concentrations of produced fluids (Pilewski et al., 2019).

Recently, studies have focused on the role of specific additives in HFF and their influence on fluid-rock interactions. Oxidative breakers are of particular interest because they can promote oxidation reactions within the naturally reduced environments that characterize organic rich shale plays. Strong oxidizers influence the redox potential of injection fluid and can potentially control chemical reaction rates in the subsurface. Studies have shown the potential for oxidative fluids to produce additional porosity and permeability through oxidative dissolution of mineral phases and organic matter in shale formations by the addition of various breakers (Hull et all., 2019, You et al., 2017, Li et al., 2020). Data provided in these studies suggests that a reactive oxidizing fluid may provide a means for improving well efficacy through increased flow paths of organic-rich shales. Li et al., 2020, provided promising results by demonstrating the removal efficiency of organic matter through the addition of oxidants hydrogen peroxide, sodium hypochlorite, and sodium persulfate to be $11 \%, 75 \%$, and $29 \%$, respectively. Additionally, the structural characteristics of kerogen have been known to affect fracture behavior during fracturing operations and their interaction with oxidative fluids should be considered. Hull et al., 2019 , found that kerogen degradation over a $20 \mathrm{~h}$ period for a suite of various shale samples with 
the oxidant sodium bromate was $81.3 \%$ on average. Previous studies involving oxidative breakers have primarily focused on the porosity changes generated by oxidative dissolution. However, these studies lack the understanding of other organic and inorganic contamination caused by oxidative breakers.

Additionally, many of these studies utilize pure solutions of HFF additives without adding other chemical additives; therefore, the actual reaction mechanisms cannot be predicted. Generally, common oxidants used in industry contain halide elements that may promote the transformation of organic compounds (Sumner et al., 2019). Similarly, the release of metals and critical minerals into solution by oxidative solutions has not been studied. A few studies have shown how common acid and oxidizing additives in HFF can influence metal leaching from shale (Tasker et al., 2016, Bank et al., 2010, Wang et al., 2015). We hypothesize that many of the major geochemical reactions during fluid-rock interactions will be influenced to various extents by different oxidative breakers. Overall, the objective of this study was to investigate the impact of commonly used oxidative breakers in HFF on release of organic contaminants, changes in major ion chemistry, and critical minerals during shale gas stimulation. The research herein will contribute to the growing knowledge of the complex chemical reactions that occur in the subsurface during hydraulic fracturing operations. This research will also help in developing better strategies for water remediation and management strategies. 


\subsection{Format of thesis:}

Chapter 1 of this thesis comprises of the literature review done in preparation of this study and for manuscript development. Chapter 2 of this thesis contains a manuscript version of this thesis for potential submissions to a scientific journal for publication. The final chapter, is a summary of the final conclusions of this thesis.

\subsection{Effect of oxidative breakers on organic matter degradation, contaminant mobility and} critical mineral release during shale-fracturing fluid interactions in the Marcellus Shale

\section{Abstract}

In recent years, the challenges associated with effective unconventional shale gas production and decline in oil and gas prices, has urged industry operations to use chemical additives in non-traditional manners in an attempt to increase hydrocarbon production. Shale treatment via oxidative dissolution has proven to enhance formation porosity and permeability. However, these fluid-rock interactions have not been extensively studied. In this study, three synthetic oxidizing hydraulic fracturing fluid (HFF) solutions were created using common industry oxidative breakers: ammonium persulfate, sodium bromate, and sodium hypochlorite. Using batch reactors, the oxidizing HFF solutions were reacted with a Marcellus Shale sample for the duration of a typical shut-in period of two weeks. To identify geochemical processes influenced by oxidative breakers, we focused analyses on the presence of organic compounds, critical minerals (metals and metalloids), mineralogy, and major ion chemistry. Results showed that individual oxidizing breakers controlled the type and amount of volatile organic compounds (VOCs) and semi-volatile organic compounds (SVOCs) present in the control and shale reacted effluents. An abundance of halogenated organic compounds was observed in effluents with sodium bromate and sodium hypochlorite, and negligible amounts were associated with 
ammonium persulfate. Additionally, the transformation of VOCs was observed both in control and shale reacted effluents. Organic acids were present in variable amounts in all effluent samples. Results show an enhanced but variable dissolution of shale organic matter and other unstable constituents such as pyrite by each oxidative fluid. This oxidation of shale organic matter and constituents stimulated the release of critical minerals into solution. Additionally, shifts in major ions and XRD results indicated that carbonate mineral dissolution and barite precipitation occurred in all shale reacted effluents. Similarly, gypsum precipitation was observed to occur in samples where sulfate ions were abundant due to enhanced dissolution of pyrite. Halite precipitation occurred in one effluent sample. These results suggest that oxidizing agents in HFF may provide a means for enhanced hydrocarbon production through oxidative dissolution; however, the generation and transformation of VOCs, critical minerals, and secondary mineral dissolution and precipitation should be considered.

\subsection{Introduction:}

Hydraulic fracturing is an advanced hydrocarbon extraction technique that has allowed oil and gas operators to efficiently and effectively tap deep organic-rich shale reservoirs once deemed inaccessible. In recent years, controversy has developed around large scale multistage hydraulic fracturing operations that require injection of on average 4.5 million gallons of freshwater to stimulate horizontal wells to achieve gas production at the economic level in shale plays like the Marcellus Shale (Mohammad-Pajooh et al., 2018). There are widespread concerns centered around the usage of freshwater resources, effects of chemical additives used in hydraulic fracturing fluid (HFF), and contamination of water and air in areas of intense hydraulic fracturing. Studies have shown that hydraulic fracturing operations have been associated with groundwater and surface water contamination, wastewater spill incidents, ecological degradation 
and socio-economic impacts (Brantley et al., 2014, U.S Environmental Protection Agency 2016, Entrekin et al. 2011, Vengosh et al. 2014, Woda et al. 2019, Llewllyn et al. 2015). However, with current oil and gas prices on the decline, the industry has been pushed to use new chemical additives such as strong oxidizers at in attempt to increase well efficiency and hydrocarbon production. Little research has been conducted on the adverse effects of chemical additives in non-traditional manners. More recently, the concern is centered on reusing and managing produced waters resulting from hydraulic fracturing operations. Currently, produced water is the most massive waste stream generated by unconventional hydrocarbon exploration (Sharma et al., 2021). Issues surrounding produced waters from unconventional operations provide unique challenges to properly handle the myriad of inorganic and organic contaminants observed in produced fluids. Conducting laboratory-scale experiments that include common additives in HFF will better understand the reactions that ensue between HFF and the target rock formation.

$\mathrm{HFF}$ is generally comprised of $95 \%$ water, $4 \%$ proppant, and $1 \%$ chemical additives (FracFocus.org). Chemical additives are a small component of HFF but are a vital component to the success and productivity of fracturing operations. Additives are selected to produce a highperformance fluid while maintaining the integrity of the wellbore. Common additives include an acid to prevent mineral scaling in the wellbore, a gelling agent to transport proppant into the fracture networks, a breaker to control fluid viscosity and a friction reducer to allow immense fluid flow (Elsner and Hoelzer, 2016). Other additives such as pH controllers, corrosion inhibitors, biocides, clay stabilizers and petroleum distillates have marginal composition but help to maintain the effectiveness of other additives (Barati and Liang, 2014). During the hydraulic fracturing process, chemical additives are added at specific times to initiate a suite of interactions within the reservoir during the shut-in period. Typically, the horizontally drilled section of the 
well is fractured in successional stages to account for the extreme lateral extent of the well. Once fractures have been opened and propagated in each stage, fracturing fluids remains in contact with the target formation during this shut-in period that can last several days to weeks. After a calculated period of time, breakers become activated to destabilize the polymer chains of the gelling agents to reduce viscosity to allow flowback of hydrocarbons from the fractures into the well. Reactions that can occur during this time include mineral dissolution and precipitation, organo-metallic complex formation, halogenation, organic matter degradation and organic and inorganic ion adsorption from clay mater (Marcon et al.,2017, Pilewski et al., 2019). These reactions affect well permeability, porosity, overall hydrocarbon production, produced water composition and contaminant release. Specifically, breakers promote several significant reactions in the subsurface because the constituents of shale formations such as organic matter, pyrite and other minerals are reduced in nature and are highly susceptible to oxidation by breakers (You et al., 2018).

Extensive laboratory studies have provided insight into the complex geochemical reactions that occur during fluids-shale interactions (Jew et al., 2017, Marcon et al., 2017, Pilewski et al., 2019, Harrison et al., 2017, Vankeuren et al., 2017). Studies have shown that major geochemical reactions are primarily influenced by shale mineralogy and fluid chemistry. Often, carbonate and iron bearing mineral dissolution and secondary mineral precipitation are evident (Jew et al., 2017, Marcon et al., 2017). Additionally, metal and trace element mobility has been observed (Harrison et al., 2017). Few studies have even demonstrated chemical additive degradation and transformation (Sumner et al., 2019, Tasker et al., 2016). Recently, studies investigating oxidative shale-fluid reactions have gained traction as strong oxidizing agents provide the potential to enhance hydrocarbon production. Studies have shown the potential for 
oxidative fluids to produce additional porosity and permeability through oxidative dissolution of mineral phases and organic matter in shale formations by adding various breakers (Hull et al., 2019, You et al., 2018, Li et al., 2020). Li et al., 2020, provided promising results by demonstrating the removal efficiency of organic matter through the addition of oxidants hydrogen peroxide, sodium hypochlorite, and sodium persulfate to be $11 \%, 75 \%$, and $29 \%$, respectively. Additionally, Hull et al., 2019 demonstrated kerogen degradation up to $79 \%$ by ammonium persulfate and sodium bromate and concluded the chemio-physical characteristics of kerogen are altered during their interaction.

Similarly, a microscopy study by You et al., 2018 observed increased interconnectivity of pore networks in shale samples by oxidative treatment. Data provided in these studies suggests that a reactive oxidizing fluid may provide a means for improving well efficacy through increased flow paths of organic rich shales. The results of these studies are promising, but because pure solutions of oxidizing agents were utilized, the true reactions of oxidizing agents in mixed HFF cannot be predicted. Additionally, these studies did not investigate the organic contaminants that may be generated by oxidative breakers through organic matter degradation, potential for enhanced trace element release, or transformation of chemical additives in HFF.

Here we investigate the fluid-rock interactions that occur between shale and different simulated oxidative hydraulic fracturing fluids using a series of batch reactor experiments. Marcellus Shale is chosen for this study because of its extensive use in previous shale-fluid experiments, distinct mineralogical composition and high TOC content. Three oxidative HFF's were synthesized using common oxidative breakers ammonium persulfate, sodium bromate and sodium hypochlorite. The objectives of this study were to: (1) determine organic contaminants present in control HFF and produced fluids reacted with shale samples, (2) identify inorganic 
species and trace metals released during reactions, (3) evaluate organic matter degradation of shale samples and (4) investigate mineralogy changes of shale samples reacted with oxidative fluids. Determining contaminant release and evolution of fluid composition is vital for mitigating environmental impacts while understanding how oxidative fluids may influence reactions in the subsurface. This work will provide insight into how oxidative breakers may be deployed in a non-traditional manner in fracturing operations of shale formations in an environmentally responsible manner.

\subsection{Materials and Methodology:}

Fluid shale batch reactions were conducted at formation temperatures $\left(\sim 100^{\circ} \mathrm{C}\right)$ to mimic the in-situ reactions between hydraulic fracturing fluid and the shale formation during the initial shut-in phase of a fracking operation. The experimental set-up and all the analyses conducted are discussed below.

\section{Sampling and preparation:}

All reactions were conducted using the LM-1 shale sample from Wetzel County, West Virginia. This sample is from a core depth of approximately 7,367 feet, has a relatively high total organic carbon content of $8.69 \%$, and is thermally mature $\left(1.61 \mathrm{R}_{0} \%\right)$. The LM1 shale sample was chosen as it is likely to contain a more significant amount of purgeable organics. Before reaction with hydraulic fracturing fluid, the shale sample was rinsed with deionized water to remove drilling fluids and crushed to 100 mesh using a mortar and pestle to increase surface area during the reactions. Shale chips ranging in size from $1 \mathrm{~cm}-5 \mathrm{~cm}$ were also broken from the original core and used in the reactions. 
The fluid used during reactions is a mixture of synthetic formation brine and synthetic hydraulic fracturing fluid (Table 1). The mixture of formation brine and fracturing fluid was prepared using the methods reported in Paukert Vankeuren et al., 2017. Proprietary chemicals used in previous studies that are no longer available were replaced with respective ingredients. These included a gelling agent WGA-15L, a clay stabilizer WCS-631LC, a friction reducer WFR-61LA, and a corrosion inhibitor WAI-251LC. Substitutes for these were based upon MSDS sheet data and common chemicals used in the same region for the same purposes as reported by FracFocus data. Petroleum distillates were used in place of the proprietary gelling agent and friction reducer, choline chloride replaced the proprietary clay stabilizer, and cinnamaldehyde replaced the proprietary corrosion inhibitor. Three different hydraulic fracturing fluid mixtures were created that included a different oxidizing breaker in each mixture. The three oxidizing breakers that were varied in each mixture were ammonium persulfate, sodium bromate and sodium hypochlorite. These breakers were chosen based on their frequency reported by FracFocus and by their proven oxidizing strength in previous studies. The concentrations of these breakers in each mixture were based on data provided by FracFocus.org and from previous studies (Hull et al., 2019, Li et al., 2018). The concentration of ammonium persulfate, sodium bromate and sodium hypochlorite in each oxidative fluid were $0.1 \mathrm{wt} / \mathrm{v} \%, 4 \mathrm{wt} / \mathrm{v} \%(0.26 \mathrm{M})$ and $6 \mathrm{wt} / \mathrm{v} \%(0.77 \mathrm{M})$ respectively. 
Table 1: Composition of the synthetic HFF and brine used during reactions. *Denotes the oxidative breaker that was altered between control fluids.

\begin{tabular}{|c|c|c|}
\hline Chemical Name & Amount & Purpose \\
\hline Hydrochloric Acid & $0.634(\mathrm{ml})$ & $\begin{array}{c}\text { Perforation } \\
\text { Cleaner }\end{array}$ \\
\hline $\begin{array}{c}\text { Ammonium Persulfate* } \\
\text { Sodium Hypochlorite } \\
\text { (0.77M)* } \\
\text { Sodium Bromate }(0.26 \mathrm{M}) *\end{array}$ & $\begin{array}{c}1(\mathrm{~g}) \\
350(\mathrm{~mL}) \\
39.2(\mathrm{~g})\end{array}$ & Oxidative Breaker \\
\hline Petroleum distillates & $1.149(\mathrm{ml})$ & Friction Reducer \\
\hline Choline Chloride & $1.06(\mathrm{~g})$ & Clay Stabilizer \\
\hline Glutaraldehyde & $0.343(\mathrm{ml})$ & Biocide \\
\hline Potassium Hydroxide & $0.0357(\mathrm{ml})$ & $\mathrm{pH}$ controller \\
\hline Potassium Carbonate & $0.24(\mathrm{~g})$ & $\mathrm{pH}$ controller \\
\hline Ethylene Glycol & $0.0222(\mathrm{ml})$ & Scale Inhibitor \\
\hline Citric Acid & $0.0336(\mathrm{~g})$ & Iron Control \\
\hline Boric Acid & $0.02(\mathrm{~g})$ & Cross Linker \\
\hline Ethanolamine & $0.0138(\mathrm{ml})$ & Cross Linker \\
\hline Cinnamaldehyde & $0.0012(\mathrm{ml})$ & $\begin{array}{l}\text { Corrosion } \\
\text { Inhibitor }\end{array}$ \\
\hline Barium Chloride Dihydrate & $0.464(\mathrm{~g})$ & Brine Component \\
\hline Potassium Chloride & $0.4162(\mathrm{~g})$ & $\mathrm{pH}$ controller \\
\hline $\begin{array}{l}\text { Strontium Chloride } \\
\text { Hexahydrate }\end{array}$ & $1.3597(\mathrm{~g})$ & Brine Component \\
\hline Ammonium Chloride & $0.16(\mathrm{~g})$ & Brine Component \\
\hline Sodium Bromide & $0.18(\mathrm{~g})$ & Brine Component \\
\hline Calcium Chloride Dehydrate & $7.4(\mathrm{~g})$ & Brine Component \\
\hline $\begin{array}{l}\text { Magnesium Chloride } \\
\text { Sesquihydrate }\end{array}$ & $1.9(\mathrm{~g})$ & Brine Component \\
\hline Sodium Chloride & $16.7(\mathrm{~g})$ & Brine Component \\
\hline Sodium Sulfate & $0.000293(\mathrm{~g})$ & Brine Component \\
\hline Sodium Bicarbonate & $0.15(\mathrm{~g})$ & Brine Component \\
\hline
\end{tabular}

Experiments were conducted using $500 \mathrm{~mL}$ borosilicate glass serum bottles. The bottles were sealed using butyl-rubber stoppers and aluminum crimp seals. The bottles, butyl-rubber stoppers, and aluminum crimp seals were washed and rinsed to eliminate trace organics and contaminants. The bottles were filled with a fixed 20:1 ratio of HFF following shale procedures reported by similar studies (Pilewski et al., 2019, Marcon et al., 2017, Dustin et al., 2018). The 
fixed 20:1 HFF to shale ratio comprises $19 \mathrm{~g}$ of powered shale, $1 \mathrm{~g}$ of shale chips, and $400 \mathrm{~mL}$ of synthetic HFF. The HFF:shale and ratio was chosen to best replicate reservoir conditions while optimizing an appropriate amount of fluid required for sampling. Reactors that contained shale were each reacted with the 3 oxidative fluids previously prepared. Oxidative HFF's were also reacted with the absence of shale to provide a control for reactions that may occur within the HFF. Reactions were conducted for a 14 -day period at $100^{\circ} \mathrm{C}$ and constantly stirred.

Table 2: Sample abbreviations of control and shale reacted effluents.

\begin{tabular}{|c|c|}
\hline Sample Nomenclature & Meaning \\
\hline $\mathrm{AMP}_{\mathrm{C}}$ & Ammonium persulfate control HFF \\
\hline $\mathrm{SB}_{\mathrm{C}}$ & Sodium Bromate control HFF \\
\hline $\mathrm{SH}$ & Sodium Hypochlorite control HFF \\
\hline AMP-LM1 & Ammonium persulfate HFF reacted with LM1 shale \\
\hline SB-LM1 & Sodium Bromate HFF reacted with LM1 shale \\
\hline SH-LM1 & Sodium Hypochlorite HFF reacted with LM1 shale \\
\hline
\end{tabular}

Analytical Methods:

Fluid properties

Fluid properties, including $\mathrm{pH}$ and oxidation-reduction potential (ORP) of each fracturing fluid, were measured before and upon completion of reaction with shale samples. A YSI Professional Plus handheld device was used to measure the fluid parameters. Before $\mathrm{pH}$ sampling, the $\mathrm{pH}$ probe was calibrated using a $\mathrm{pH}-4$ and $\mathrm{pH}-7$ buffer to ensure accurate readings. Before ORP measurements, the ORP probe was calibrated using a Zoebell solution. The $\mathrm{pH}$ and ORP probe's accuracies were \pm 0.1 and $\pm 0.5 \mathrm{mV}$, respectively. Sampling was conducted using $15 \mathrm{~mL}$ aliquots of unreacted and reacted fracturing fluids. The $\mathrm{pH}$ and oxidation reduction potential (ORP) of unreacted fracturing fluids were sampled upon the synthesis of each fluid and 
were measured immediately upon completion of reactions to warrant any changes in fluid chemistry.

\section{Fluid Sample Collection}

Upon completion of the 14-day in situ shale-HFF reactions, fluid samples were collected for ion chromatography (IC), inductively coupled plasma optical emissions spectrometry (ICPOES) and mass spectrometry (ICP-MS), volatile organic compounds (VOC), non-purgeable organic carbon (NPOC) and dissolved inorganic carbon (DIC) analysis.

Samples collected for IC and ICP-MS analysis were collected using a high-density polyethylene Leur-Lock syringe in pre-cleaned $15 \mathrm{~mL}$ polyethylene vials with minimum headspace. IC and ICP-MS samples were filtered before the analysis via a $0.22 \mathrm{um}$ and $0.45 \mathrm{um}$ Whatman syringe filter attachment respectively. ICP-MS samples were also acidified using 6N nitric acid as $1 \mathrm{wt} \%$ of the total volume of the collected sample. IC analysis was conducted at the National Energy Technology Laboratory (NETL) Brine Chemistry Laboratory in Pittsburgh Pennsylvania on a ThermoFisher ICS-5000+ with AS11-HC column for anion and CS16 column for cation quantification. ICP-MS was conducted at the NETL Pittsburgh Analytical Laboratory (PAL) facility using a Perkin Elmer Nexion 300D instrument. Separate effluents were taken from each ICP-MS sample and analyzed at the PAL via ICP-OES for $\mathrm{Ba}, \mathrm{Ca}, \mathrm{Na}, \mathrm{Sr}$ and $\mathrm{Zn}$ using a Perkin Elmer DV 7300.

Samples for NPOC and DIC were analyzed at the NETL Pittsburgh Environmental Geochemistry facility via a Shimadzu Total Organic Carbon/Total Inorganic Carbon analyzer. Samples collected for this analysis were not filtered and placed into 50mL pre-cleaned glass vials and chilled to $4 \circ \mathrm{C}$ until analysis. 
Aliquots for VOC were sampled using a polyethylene Leur-Lock syringe and placed into $40 \mathrm{~mL}$ volatile organic analysis amber vials acidified with $\mathrm{HCl}$ to preserve analytes. Samples were immediately placed onto ice and transported to PACE analytical Morgantown and analyzed within 24hours of collection. VOC samples were analyzed following procedures of the EPA 8260B method. This method introduces VOC's into a gas chromatograph via a purge and trap method. Analytes are directly eluted from the aqueous sample and directly introduced to a capillary column before being flashed evaporated into the gas chromatograph mass spectrometer for quantification. VOC analysis was conducted using an Agilent Technologies 7890 gas chromatograph (GC) coupled with an Agilent Technologies 5975 Triple Axis mass selective detector (MSD).

Samples for polycyclic aromatic hydrocarbons (PAH) were sampled using a polyethylene Leur-Lock syringe into $100 \mathrm{~mL}$ amber glass vials. Samples were immediately placed onto ice and transported to PACE analytical Morgantown and analyzed with 24hours of collection. PAH samples were analyzed in accordance with the EPA 8270D method. PAH analysis was conducted using an Agilent Technologies 7890 gas chromatograph (GC) coupled with an Agilent Technologies 5975 Triple Axis mass selective detector (MSD).

$X R D$

Mineral composition analysis via X-Ray diffraction (XRD) was performed on powdered shale samples prior to and upon completion of reactions. Shale samples were first powdered to 400 mesh using a mortar and pestle. Shale samples that were reacted with HFF were oven dried prior to XRD analysis. Approximately $3 \mathrm{~g}$ of shale sample was mixed with fluorspar to a 90:10 weight basis and mixed via a SPEX industry Mill for 10 minutes. The x-ray intensity of the standard spike was used as a reference to determine the shale content. XRD data were collected 
using a Siemens D500 computer-automated diffractometer using Bragg-Brentano geometry. $\mathrm{Cu}$ radiation was produced at a power of $45 \mathrm{kV}$ and $30 \mathrm{~mA}$ and the diffracted beam was collimated by a 0.05 slit. Data were collected in the $2 \theta$ range of $4.9^{\circ}-66.1^{\circ}$ with a step size of $0.015^{\circ}$ and a dwell time of $1 \mathrm{sec} /$ step using a Ketek Vitus H150 high-resolution silicon drift detector with an Amptek PX5 pulse processor. Proprietary Bruker AXS software Diffrac Plus EVA was used for qualitative analysis of the XRD patterns. The International Center for Diffraction Data database was utilized for pattern matching. The whole pattern fitting function of Diffrac Plus Topas R was used for quantitative phase analysis based on the Inorganic Crystal Structure Database reference. XRD analysis was conducted at Pittsburgh Mineral and Environmental Technology (PMET) laboratory in New Brighton PA.

Shale total organic carbon (TOC)

Upon completion of the HFF-shale reactions, shale samples were analyzed for changes in TOC content. Shale samples were collected from the reactors by filtering out any remaining HFF. The shale was then oven dried at $50{ }^{\circ} \mathrm{C}$ overnight. Approximately $200 \mathrm{mg}$ of each reacted shale were placed into $5 \mathrm{~mL}$ borosilicate vials and saturated with $1 \mathrm{M} \mathrm{HCl}$ acid to remove the remaining carbonate minerals. The vials were vortexed using a Scientific Industries Vortex Genie 2 for a 3 -minute period and were left saturated for a 24-hour period. The $\mathrm{HCl}$ acid was decanted from the vials and was re-filled with additional $\mathrm{HCl}$ acid until effervesce from the shale samples was not observed. This step was repeated as necessary. The remaining acid was decanted, and the vials were filled and rinsed with deionized water to neutralize the shale. The vials were placed into a Beckman Coulter Allegra X-22 Centrifuge at 3000rpm for a 3-minute period to settle the shale samples between each decanting step, repeated 6-7 times until fully neutralized. The decarbonized shale samples were oven-dried at $50^{\circ} \mathrm{C}$ until analysis. TOC 
analysis was conducted on a Costech ECS 4010 combustion elemental analyzer (EA), coupled to a Delta Advantage isotope ratio mass spectrometer via a ConFlo IV interface in the IsoBioGeM laboratory at West Virginia University.

\subsection{Results}

\section{Aqueous Organic Chemistry}

The VOCs were observed in each oxidative control fluid after subjection to temperatures, mimicking reservoir conditions. The number of organic compounds observed in the control fluids was 10 in AMPc, 14 in SBc, and 24 SHc (Figure 1). The highest concentration of VOCs in the control samples was observed in AMPc $(100,020 \mathrm{ug} / \mathrm{l})$, followed by SBc $(96,511 \mathrm{ug} / \mathrm{l})$ and SHc $(15,799 \mathrm{ug} / \mathrm{l})$. The majority of the VOCs identified were lower $(<600 \mathrm{ug} / \mathrm{l})$ among control fluids, however, VOCs such as acetone, bromodichloromethane, bromoform, carbon disulfide, chloroform, and 2-butanone (MEK) were ubiquitous in all the control fluids. These compounds ranged in concentration from 1,000-100,000 ug/l (Figure 1 and Table S1). BTEX compounds were not detected in SBc and SHc and benzene was detected with a minimal concentration of $0.172 \mathrm{ug} / \mathrm{l}$ in AMPc. Additionally, non-halogenated organic compounds were dominantly present in AMPc while halogenated organic compounds comprised a majority of the total VOC concentration in SBc and SHc.

In the shale-oxidative fluid reactions, a myriad of organic compounds were also identified in effluents. Total VOC concentrations were $7880 \mathrm{ug} / \mathrm{l}$ in AMP-LM1, 121,822 ug/l in SB-LM1 and 35,071 ug/l in SH-LM1 (Figure 2). With respect to the control fluids, total VOC concentrations significantly decreased by $92 \%$ in AMP-LM1 but total VOC concentrations increased $26 \%$ in SB-LM1 and 122\% in SH-LM1. The number of organic compounds detected 
in effluents reacted with LM1 shale were 15 in AMP-LM1, 13 in SB-LM1 and 30 in SH-LM1

(Figure 1 and Table S2). Similar to the control fluids, several organic compounds were ubiquitous in shale-reacted effluents. These compounds include, acetone, benzene, carbon disulfide, chloroethane, 2-butanone (MEK), and methylene chloride. Correspondingly, nonhalogenated organic compounds were abundantly present in AMP-LM1 while halogenated organic compounds mainly comprised SB-LM1 and SH-LM1. SB-LM1 had high observable concentrations (mean 25,000 ug/l) of organobromides while SH-LM1 had abundant but relatively low concentrations $(<228 \mathrm{ug} / \mathrm{l})$ of chlorinated organic compounds with the exception of chlorodibromomethane that had a peak concentration of 13,200 ug/l. The highest BTEX concentrations were observed in SH-LM1 (68 ug/l), followed by AMP-LM1 (14 ug/l), and SBLM1 (9 ug/l).

A total of 19 SVOCs in the form of polycyclic aromatic hydrocarbons (PAHs) were analyzed in effluent samples and measured at levels above the method detection limit (MDL) (Table S3). PAH concentrations were detected at low concentrations in 3 effluent samples. 1methylnapthalene was measured at $0.0265 \mathrm{ug} / \mathrm{l}$ in SBc and $0.0311 \mathrm{ug} / \mathrm{l}$ in SHc. AMP-LM1 was the only shale reacted effluent to contain measurable PAHs and contained $0.0252 \mathrm{ug} / \mathrm{l}$ Chrysene and $0.0141 \mathrm{ug} / \mathrm{l}$ Fluoranthene.

Effluent samples contained six observable organic acids: acetate, propionate, formate, butyrate, succinate and oxalate. Total organic acid concentrations ranged from $36.1 \mathrm{mg} / \mathrm{l}$ to 57.8 $\mathrm{mg} / \mathrm{l}$ in the control fluids and $25.8 \mathrm{mg} / \mathrm{l}$ to $136.6 \mathrm{mg} / \mathrm{l}$ in the shale reacted effluents. In comparison to the control fluids, organic acid concentrations increased in shale reacted effluents SB-LM1 and SH-LM1 and decreased in AMP-LM1 (Figure 3). AMPc contained $7.27 \mathrm{mg} / 1$ acetate, $8.39 \mathrm{mg} / \mathrm{l}$ formate, $40.183 \mathrm{mg} / \mathrm{l}$ succinate and $2.042 \mathrm{mg} / \mathrm{l}$ oxalate. $\mathrm{SBc}$ contained 6.26 
$\mathrm{mg} / \mathrm{l}$ acetate, $4.15 \mathrm{mg} / \mathrm{l}$ propionate, $9.17 \mathrm{mg} / \mathrm{l}$ formate, $4.03 \mathrm{mg} / \mathrm{l}$ butyrate, $19.904 \mathrm{mg} / \mathrm{l}$ succinate and $11.041 \mathrm{mg} / \mathrm{l}$ oxalate. SHc contained $8.09 \mathrm{mg} / \mathrm{l}$ acetate, $4.13 \mathrm{mg} / \mathrm{l}$ propionate, $6.03 \mathrm{mg} / \mathrm{l}$ formate, $3.99 \mathrm{mg} / \mathrm{l}$ butyrate and $13.874 \mathrm{mg} / \mathrm{l}$ succinate. AMP-LM1 decreased in total organic acid concentration by $55 \%$ as compared to the control sample and contained $5.28 \mathrm{mg} / \mathrm{l}$ acetate, $4.09 \mathrm{mg} / \mathrm{l}$ propionate, $8.65 \mathrm{mg} / \mathrm{l}$ formate, $5.169 \mathrm{mg} / \mathrm{l}$ succinate and $2.623 \mathrm{mg} / \mathrm{l}$ oxalate. SB-LM1 increased in total organic acid concentration by $62 \%$ (compared to control sample SBc) and contained $27.22 \mathrm{mg} / \mathrm{l}$ acetate, $6.23 \mathrm{mg} / \mathrm{l}$ propionate, $8.16 \mathrm{mg} / \mathrm{l}$ formate, $4.78 \mathrm{mg} / \mathrm{l}$ butyrate, $10.498 \mathrm{mg} / \mathrm{l}$ succinate and $31.364 \mathrm{mg} / \mathrm{l}$ oxalate. LM1-SH significantly increased $278 \%$ in total organic acid concentration and contained $61.34 \mathrm{mg} / \mathrm{l}$ acetate, $6.63 \mathrm{mg} / \mathrm{l}$ propionate, $27.64 \mathrm{mg} / \mathrm{l}$ formate, $4.61 \mathrm{mg} / \mathrm{l}$ butyrate, $16.208 \mathrm{mg} / \mathrm{l}$ succinate and $20.119 \mathrm{mg} / \mathrm{l}$ oxalate (Table 3).

Table 3: Organic acid concentrations in control and shale reacted effluents. *ND - Not Detected

\begin{tabular}{|c|c|c|c|c|c|c|c|}
\hline & Acetate & Propionate & Formate & Butyrate & Succinate & Oxalate & Total \\
\hline & $\mathrm{mg} / \mathrm{L}$ & $\mathrm{mg} / \mathrm{L}$ & $\mathrm{mg} / \mathrm{L}$ & $\mathrm{mg} / \mathrm{L}$ & $\mathrm{mg} / \mathrm{L}$ & $\mathrm{mg} / \mathrm{L}$ & $\mathrm{mg} / \mathrm{l}$ \\
\hline AMPc & 7.27 & $\mathrm{ND}$ & 8.39 & $\mathrm{ND}$ & 40.183 & 2.042 & 57.885 \\
\hline SBc & 6.26 & 4.15 & 9.17 & 4.03 & 19.904 & 11.041 & 54.555 \\
\hline SHc & 8.09 & 4.13 & 6.03 & 3.99 & 13.874 & $\mathrm{ND}$ & 36.114 \\
\hline AMP-LM1 & 5.28 & 4.09 & 8.65 & $\mathrm{ND}$ & 5.169 & 2.623 & 25.812 \\
\hline SB-LM1 & 27.22 & 6.23 & 8.16 & 4.78 & 10.498 & 31.364 & 88.252 \\
\hline SH-LM1 & 61.34 & 6.63 & 27.64 & 4.61 & 16.208 & 20.119 & 136.547 \\
\hline
\end{tabular}

Dissolved organic carbon (DOC) was represented as non-purgeable organic carbon (NPOC). NPOC concentrations varied from 185 to $459 \mathrm{mg} / \mathrm{l}$ and decreased in shale reacted effluents except for SH-LM1 (Figure 3 and Table 4). NPOC was measured at $316.1 \mathrm{mg} / \mathrm{l}$ in AMPc, $297.7 \mathrm{mg} / \mathrm{l}$ in SBc, $185.0 \mathrm{mg} / \mathrm{l}$ in SHc, $277.0 \mathrm{mg} / \mathrm{l}$ in AMP-LM1, $284.6 \mathrm{mg} / \mathrm{l}$ in SB-LM1, and $458.9 \mathrm{mg} / \mathrm{l}$ in SH-LM1. TOC analysis of the original shale sample LM1 was measured at 
$8.69 \pm 0.09 \%$. The TOC of reacted shale samples was measured to be $9.06 \pm 0.09 \%$ in AMPLM1, $8.67 \pm 0.09 \%$ in SB-LM1 and $5.59 \pm 0.06 \%$ in SH-LM1.

Solid shale TOC analysis shows that unreacted LM1 shale consists of 8.69 wt.\% carbon. The solid shale TOC of LM1 was observed to vary after reaction with each oxidative HFF solution. The solid shale TOC of LM1 shale increased to $9.06 \mathrm{wt} . \%$ in AMP-LM1 but decreased to $8.67 \mathrm{wt} . \%$ and $5.59 \mathrm{wt} . \%$ in SB-LM1 and LM1-SH respectively (Table 4).

Table 4: TOC (\% C) content of the reacted shale samples and NPOC concentrations (mg/l).

\begin{tabular}{|c|c|c|c|c|c|c|}
\hline & AMPc & SBc & SHc & AMP-LM1 & SB-LM1 & SH-LM1 \\
\hline NPOC & 316.1 & 297.7 & 185.0 & 277.0 & 284.6 & 458.9 \\
\hline TOC & - & - & - & $9.06 \pm 0.09$ & $8.67 \pm$ & $5.59 \pm 0.06$ \\
& & & & & 0.09 & \\
\hline
\end{tabular}

\section{Critical Minerals}

Elemental analysis (ICP-MS and ICP-OES) shows an abundance of critical minerals (metals and metalloids) in the control fluids and shale reacted effluents (Table S4). The critical mineral distribution varied significantly across effluents samples. Elements observed in trace amounts in this study include $\mathrm{Li}, \mathrm{B}, \mathrm{Al}, \mathrm{Ti}, \mathrm{V}, \mathrm{Cr}, \mathrm{Mn}, \mathrm{Fe}, \mathrm{Co}, \mathrm{Cu}, \mathrm{As}, \mathrm{Se}, \mathrm{Mo}, \mathrm{Ag}, \mathrm{Cd}, \mathrm{Sb}, \mathrm{Tl}$, $\mathrm{Pb}, \mathrm{U}$, and $\mathrm{Zn}$. Trace metal concentrations in the control fluids were 589.2 ug/l in AMPc, 1185.6 $\mathrm{ug} / \mathrm{l}$ in SBc, and $478.7 \mathrm{ug} / \mathrm{l}$ in SHc. In the control fluids, the most abundant critical minerals were Se and $\mathrm{Zn}$ with concentrations $>300 \mathrm{ug} / \mathrm{l}$. All other trace critical minerals in the control fluids had lower concentrations ranging from $0.82 \mathrm{ug} / \mathrm{l}$ to $188 \mathrm{ug} / \mathrm{l}$. All critical mineral concentrations 
were observed to be significantly higher in the shale reacted effluents (Figure 4, Figure 5,

Figure 6). Critical mineral concentrations in the shale reacted effluents were $4590.4 \mathrm{ug} / \mathrm{l}$ in AMP-LM1, 24,751 ug/l in SB-LM1 and 23,342 ug/l in SH-LM1 (Figure 7). The highest concentration critical minerals in the shale reacted effluents were $\mathrm{Al}$ and $\mathrm{Zn}$. Peak $\mathrm{Al}$ and $\mathrm{Zn}$ concentrations were observed in LM1-SH and measured $3516.8 \mathrm{ug} / \mathrm{l}$ and 14,730 ug/l, respectively. The concentrations of $\mathrm{Co}, \mathrm{Cu}, \mathrm{Mn}$, and $\mathrm{Se}$ ranged from $511 \mathrm{ug} / \mathrm{l}$ to $4571 \mathrm{ug} / \mathrm{l}$, while all other trace elements were lower than $260 \mathrm{ug} / \mathrm{l}$. Of the trace elements $\mathrm{Li}, \mathrm{Al}, \mathrm{Co}, \mathrm{Cu}$, and $\mathrm{Cd}$ were released orders of magnitude higher in SB-LM 1 and SH-LM1 than in AMP-LM1 with respect to the control fluids (Table S4). Other metals and metalloids including B, Mg, Si, K, Ca, $\mathrm{Na}, \mathrm{Sr}, \mathrm{Ba}$, and $\mathrm{Fe}$ were detected at elevated concentrations in both control and shale reacted effluents. In the control fluids the remaining metals had concentrations of $10,809.9 \mathrm{mg} / \mathrm{l}$ in AMPc, 16,997.2 mg/l in SBc and 39,409 mg/l in SHc. These metals were generally lower in shale reacted effluents with concentrations of 10,745.3 mg/l in AMP-LM1, 17,427.9 mg/l in SBLM1 and 37,710.1 mg/l in SH-LM1. It is also important to note that metals including Be, Co, $\mathrm{Mo}, \mathrm{Ag}, \mathrm{Cd}, \mathrm{Sb}, \mathrm{Tl}$, and $\mathrm{U}$ were not observed in the control fluids but had measurable concentrations in the shale reacted effluents.

\section{Mineralogy and Aqueous inorganic chemistry}

XRD results show that unreacted LM1 shale is mainly comprised of quartz, mica and orthoclase with smaller fractions of plagioclase, calcite, dolomite, pyrite, marcasite, and barite. A variable change in mineralogy was observed in the LM1 shale sample after reaction with each oxidative HFF. Calcite and dolomite concentrations decreased in all of the reacted shale samples, while barite concentrations increased. Pyrite and marcasite were observed to increase in AMPLM1 but decreased in SH-LM1 and was not detected in SB-LM1. Orthoclase, plagioclase and 
mica content varied among the reacted shale samples. Gypsum was detected in LM1-SH and LM1-SB only and halite was detected in LM1-SH. A detailed description of the unreacted and reacted shale samples is supplied in Table 5 and Figure 8.

Table 5: Quantitative XRD results of the original shale and reacted shale samples. Mineralogical composition is represented by weight percent with quantitative error of $\pm 1 \%$. $* \mathrm{ND}-$ Not Detected.

\begin{tabular}{|c|c|c|c|c|c|}
\hline & LM1 & AMP-LM1 & SH-LM1 & SB-LM1 & Formula \\
\hline quartz & 31 & 29.9 & 28.1 & 32.1 & $\mathrm{SiO}_{2}$ \\
\hline K-feldspar & 8.6 & 10.3 & 10.4 & 11 & $\mathrm{KAlSi}_{3} \mathrm{O}_{8}$ \\
\hline plagioclase & 4 & 4 & 6 & 4.5 & $(\mathrm{Na}, \mathrm{Ca})\left(\mathrm{Si}, \mathrm{Al}_{4} \mathrm{O}_{8}\right.$ \\
\hline mica & 43.6 & 45.4 & 40.9 & 47.1 & $\mathrm{KAl}_{2}\left(\mathrm{AlSi}_{3} \mathrm{O}_{10}\right)(\mathrm{OH})_{2}$ \\
\hline calcite & 0.3 & 0.2 & $\mathrm{ND}$ & $\mathrm{ND}$ & $\mathrm{CaCO}_{3}$ \\
\hline dolomite & 4.9 & 1.3 & 2 & $\mathrm{ND}$ & $\mathrm{CaMg}_{2}\left(\mathrm{CO}_{3}\right)_{2}$ \\
\hline pyrite & 5 & 5.6 & 2.8 & $\mathrm{ND}$ & $\mathrm{FeS}_{2}$ \\
\hline marcasite & 0.7 & 0.8 & 0.6 & $\mathrm{ND}$ & $\mathrm{FeS}_{2}$ \\
\hline gypsum & $\mathrm{ND}$ & $\mathrm{ND}$ & 1.2 & 3.2 & $\mathrm{CaSO}_{4}-2\left(\mathrm{H}_{2} \mathrm{O}\right)$ \\
\hline barite & 1.9 & 2.5 & 2.4 & 2.1 & $\mathrm{BaSO}_{4}$ \\
\hline halite & $\mathrm{ND}$ & $\mathrm{ND}$ & 5.6 & $\mathrm{ND}$ & $\mathrm{NaCl}$ \\
\hline
\end{tabular}

The $\mathrm{pH}$ of shale reacted effluents AMP-LM1 and SB-LM1 showed an increase from 2.80 to 5.74 and 3.19 to 3.76 respectively. The $\mathrm{pH}$ of SH-LM1 decreased from 10.88 to 4.98 .

Dissolved inorganic carbon (DIC) was detected in all control fluids and showed an increase in all shale reacted effluents. DIC was measured at $31.8 \mathrm{mg} / \mathrm{l}$ in AMP-LM1 (vs $0.54 \mathrm{mg} / \mathrm{l}$ in AMPc), $64.8 \mathrm{mg} / 1$ in SB-LM1 (vs $2.26 \mathrm{mg} / 1$ in SBc), and $71.9 \mathrm{mg} / 1$ in SH-LM1 (vs $37.8 \mathrm{mg} / \mathrm{l}$ in SHc). IC results show that $\mathrm{Ba}$ was not detected in $\mathrm{AMPc}$, but was measured at $59.8 \mathrm{mg} / \mathrm{l}$ in $\mathrm{SBc}$ and 179.6 $\mathrm{mg} / \mathrm{l}$ in SHc. Barium decreased below detection limits in all shale-reacted effluents. All shalereacted effluents show an increase in sulfate relative to their respective control fluids. Sulfate was highest in SB-LM1 measured at $2715.2 \mathrm{mg} / \mathrm{l}$, followed by $1137.2 \mathrm{mg} / \mathrm{l}$ in SH-LM1 and 602.6 mg/l in AMP. Phosphate followed a similar trend as sulfate. Phosphate was not detected in AMP-LM1 but had measurable concentrations of $19.9 \mathrm{mg} / \mathrm{l}$ in SB-LM1 and $34.6 \mathrm{mg} / \mathrm{l}$ in SH- 
LM1. Potassium concentrations were consistent in all control fluids and slightly increased in all shale reacted effluents with no observable trends. Sodium and chloride concentrations were consistent between all control and shale reacted effluents except for SHc and SH-LM1. Chloride concentrations were 56,551 mg/l in SHc and 69,479 mg/l SH-LM1 and sodium was measured at 38,343 mg/l in SHc and 39,994 mg/l in SH-LM1. Calcium, Mg and Na had variable concentrations in all control and shale reacted effluents with no noticeable trends. The high concentrations of $\mathrm{Ca}, \mathrm{Mg}, \mathrm{Na}$, and $\mathrm{K}$ added to the synthetic HFF's, makes it very difficult to interpret the changes and differences in their concentrations in the shale reacted effluents (Table 6).

Table 6: Major anion and cation concentrations as measured by IC.

\begin{tabular}{|c|c|c|c|c|c|c|c|c|c|c|}
\hline & Sulfate & Chloride & Phosphate & Sodium & Ammonium & Potassium & Magnesium & Calcium & Strontium & Barium \\
\hline & $\mathrm{mg} / \mathrm{L}$ & $\mathrm{mg} / \mathrm{L}$ & $\mathrm{mg} / \mathrm{L}$ & $\mathrm{mg} / \mathrm{L}$ & $\mathrm{mg} / \mathrm{L}$ & $\mathrm{mg} / \mathrm{L}$ & $\mathrm{mg} / \mathrm{L}$ & $\mathrm{mg} / \mathrm{L}$ & $\mathrm{mg} / \mathrm{L}$ & $\mathrm{mg} / \mathrm{L}$ \\
\hline AMPc & 478.99 & 15789.0 & 6.13 & 6446.79 & 201.40 & 268.93 & 141.60 & 1551.24 & 214.78 & ND \\
\hline SBc & 6.20 & 15671.6 & 10.26 & 13501.37 & $\mathrm{ND}$ & 274.55 & 183.92 & 2150.08 & 395.90 & 59.83 \\
\hline SHc & 5.40 & 56551.2 & $\mathrm{ND}$ & 38343.55 & $\mathrm{ND}$ & 284.28 & 106.37 & 1046.35 & 305.25 & 179.64 \\
\hline AMP-LM1 & 602.6 & 15834.7 & $\mathrm{ND}$ & 7201.58 & 198.69 & 311.30 & 237.26 & 1999.81 & 124.17 & ND \\
\hline SB-LM1 & 2715.2 & 15374.5 & 19.934 & 13903.17 & $\mathrm{ND}$ & 307.02 & 340.28 & 2074.04 & 48.50 & ND \\
\hline SH-LM1 & 1137.2 & 69479.5 & 34.60 & 39944.55 & 2.82 & 321.22 & 97.02 & 1828.68 & 271.26 & ND \\
\hline
\end{tabular}

\subsection{Discussion:}

\section{Effect of breakers on $\mathrm{VOC}$ release}

The VOCs in gaseous and solubilized forms are ubiquitous in most hydraulic fracturing operations. However, most of the lab-scale fluid-shale experiments conducted to understand the release of VOCs have focused on BTEX compounds (Pilewski et al., 2019, Marcon et al., 2017). In this study, we document the presence of 73 VOCs occurring in variable concentrations across all reactions, including control fluids and shale reacted effluents. All target analyte 
concentrations were measured at levels higher than the method detection limit (MDL) (Table S1 and Table S2).

The presence of target VOCs in all control fluids indicates, that the formation of a portion of the total VOCs can be attributed to the transformation of additives within the synthetic HFF without any interaction with shale constituents. For example, carbon disulfide is a known degradation product of some friction reducers and the biocide glutaraldehyde (Kahrilas et al., 2015). A similar degradation process may have occurred with glutaraldehyde and other additives in our effluents. The generation mechanism of different VOCs was beyond the scope of this preliminary study. However, the type and amount of VOCs generated appears to be controlled by oxidizing strength and chemical specificity of different breakers. Acetone was detected in all control fluids with a peak concentration of 100,000 ug/l in AMPc. Acetone synthesis can occur by the oxidation of propylene in the presence of reactive radical species (Sifniades et al., 2011). During ammonium persulfate degradation, highly reactive sulfate free radicals are generated and may have specifically oxidized propylene, resulting in the anomalously high concentration of acetone in AMPc. Propylene is possibly a proprietary ingredient in the petroleum distillate added to the HFF solutions and may explain why acetone was ubiquitous in all effluent samples. Additionally, our data shows the generation of halogenated organic compounds was specifically controlled by the halogen derived oxidative breakers (sodium bromate and sodium hypochlorite). Oxidant's sodium bromate (used in SBc) and sodium hypochlorite (used in SHc), possibly resulted in the production of halogenated organic compounds in their respective control effluents. The effluents of SBc and SHc, show abundance of organobromides and chlorocarbon compounds such as bromodichloromethane, bromoform, chlorodibromomethane, and chloroform (Figure 1 and Table S1). In contrast, AMPc produced negligible halogenated organic 
compounds. These results suggest that organobromides and chlorocarbons can be generated by the reaction between the halogenated oxidants and other constituents in HFF. When injected into the target formation, they may undergo further transformation on interaction with the constituents of the formation.

The increase in VOCs, including BTEX concentrations in shale reacted effluents compared to control fluids, indicates that additional VOCs are produced by the reaction of breakers with shale organic matter via potential oxidative transformation (Hull et al., 2019, You et al., 2017, Pilewski et al., 2019). BTEX compounds have been identified in similar lab-scale experimental studies and in produced waters of the Marcellus Shale (Ziemkiewicz and He, 2015, Elsner and Hoelzer, 2016, Marcon et al., 2017, Pilewski et al., 2019). Large macromolecules within the organic matrix of the LM1 shale sample may be prone to solubilization by HFF interaction via oxidative transformation. The discrepancy in BTEX concentrations between LM1 shale reacted effluents, suggests the effectiveness of organic matter degradation depends on the type and strength of oxidative breaker. The significant increase in BTEX compounds observed in SH-LM1 indicates that sodium hypochlorite may react more readily with shale organic matter than the other breakers. This in turn will enhance the release of BTEX compounds. Similarly, the highest VOC concentrations correlated with higher ORP of the oxidative HFF used during the reaction (Figure 2). In addition to the degradation of shale organic matter, VOCs may be sourced by the transformation of VOCs that are already present in the control fluids.

The transformation of VOCs in reaction with shale is evident by comparing specific compounds in shale reacted effluent samples with the control fluids. For example, bromoform, chloroform, and other trihalomethanes were detected at elevated concentrations in the controls of SBc and SHc, respectively. The concentrations of bromoform and chloroform decreased 
significantly in their respective shale reacted effluents (SBc to SB-LM1, and SHc to SH-LM1), potentially due to the transformation or degradation of these compounds. The transformation of the trihalomethanes in the control fluids, may have generated the additional trihalomethanes detected at elevated concentrations in the shale reacted effluents (Figure 1 and Table S2). This suggests that the trihalomethanes produced in the control fluids may interact with shale organic matter to produce additional chlorinated and organobromide bi-products. It is important to note that specific chlorinated and organobromide compounds such as bromobenzene, 2-chlorotoluene, and trichloroethene were not detected in the control fluids, supporting that these additional compounds may have been produced by degradation and transformation of VOCs in control fluids or by interaction with shale organic matter. In contrast, AMPc and AMP-LM1 do not show any presence of halogenated compounds because these samples did not contain any halogenderived additives.

\section{Effect of breakers on Semi-Volatile Organic Compounds (SVOCs)}

Our results are similar to those of produced fluids sampled during field operations such that PAHs were in the low ug/l range (Butkovskyi et al., 2017). PAHs are found in large quantities in coalbed methane-produced waters due to the leeching from coal organic matter (Orem et al., 2007). PAHs are also identified in trace amounts in produced waters related to shale gas operations (Orem et al., 2014, Hayes et al., 2012). The observed low concentration of 1Methylnapthalene in $\mathrm{SBc}$ and $\mathrm{SHc}$ may be attributed to the transformation of organic compounds sourced from the petroleum distillates added to each HFF. The proprietary ingredients and additives of petroleum distillates are poorly characterized and warrant separate investigation for evidence of PAHs. On the other hand, our results show that PAHs were solubilized during fluidrock interactions in AMP-LM1 and may be subject to oxidative dissolution by breakers. 
However, with a limited amount of data, the extent of PAH mobilization cannot be determined. It is possible that other PAHs were proliferated during our oxidative HFF reactions and were effectively adsorbed to the shale organic matter. However, the absence of PAHs in our effluents is a positive result as it lowers the toxic effect of produced waters. Further studies are needed to determine the mechanisms that release PAHs during fluid-shale interactions.

Of the target VOC and SVOC analytes, halogenated hydrocarbons, BTEX compounds, and PAHs are of most significant concern due to their toxicity, relatively high solubility, and potential for persistence in the environment (Hawboldt et al., 2005). The presence of these compounds in fracturing operations and fluid-shale studies presents unique challenges associated with produced water treatment, water re-use, and environmental concerns relating to water resource contamination. Compound's such as benzene, carbon tetrachloride, chloroform, 1,2Dichloroethane, methylene chloride, many chlorocarbons and organobromides detected in our study, are considered carcinogenic (Lewis et al., 2004). Many VOCs and SVOCs have adverse health effects after long-term exposure predominantly affecting respiratory function, can impair human development and endocrine cycles, and cause various cell mutations leading to cancer in humans (Soni et al., 2018, Bekki et al., 2013). PAHs are the greatest threat to human health as concentrations as little as $0.2 \mathrm{ug} / \mathrm{l}$ in drinking water resources can have devastating health effects (U.S. EPA, 1985). PAH concentrations in our samples were less than $0.2 \mathrm{ug} / \mathrm{l}$, however, these breakers may react and initiate the release of more PAHs if they are used in higher concentration or the reaction time is different (shorter or longer). Therefore, further studies are needed to better understand the role of these breakers on PAH release.

Currently, various treatment strategies exist for the removal of organic compounds from shale gas-related operations. These remediation strategies include basic separation, activated 
carbon adsorption, membrane separation, biological treatment, thermal distillation, and advanced oxidation with varying success rates at removing halogenated compounds, VOCs, and PAHs (Butkovskyi et al., 2017). However, depending on the type and amount of organic compounds present, alternative treatment strategies may be necessary. Our study indicates that variable type and amount of VOCs and PAHs could be released by using different oxidative breakers indicating site specific remediation strategies may be required for water treatment and management.

\section{Effect of breakers on Organic Acids and NPOC}

Our results indicate organic acids are generated in all control fluids when subject to temperatures mimicking reservoir conditions. In particular, acetate, formate and succinate were dominant in all of the control fluids. The generation of organic acids observed in the control fluids indicates that the transformation or degradation of organic additives in the HFF's may be a source of organic acids. The degradation of organic additives such as ethoxylates, gaur gum, and glycols can result in organic acid generation (Luek et al., 2017). Other studies have also observed the proliferation of organic acids in synthetic HFF's and shale-produced fluids during laboratory fluid-shale reactions (Pilewski et al., 2019, Marcon et al., 2017, Hoelzer et al., 2016). However, our data show an increase in total organic acid concentration in shale-reacted effluents SB-LM1 and SH-LM1. This result suggests organic acids could be released from shale organic matter. Acetate is a known product of the thermal cracking of source rock kerogen (Kharaka., et al 1983), and oxidative dissolution of kerogen may release bound functional groups (Hull et al., 2019).

Similarly, ester linked carboxyl functional groups are attached to the organic matter in shale, and it is believed that these functional groups can become extracted during the fracturing 
process of shale gas operations and explain the concentrations of low molecular weight carboxyl acids (Zhu et al., 2015). Additionally, organic acids are also known to be produced by microbial fermentation under the anaerobic conditions of hydraulic fracturing operations (Muller, 2001). Microbial communities capable of producing organic acids have been identified in Marcellusproduced waters where acetate was present (Murali Mohan et al., 2013, Cluff et al., 2014). However, the concentration of organic acids in shale reacted effluents may also be dominantly controlled by the oxidative strength of the HFF. Our results show the most considerable variation in total organic acid concentration was present between SBc to SB-LM1 and SHc to SH-LM1. This suggests that sodium bromate and sodium hypochlorite breakers may be most effective at increasing organic acids by oxidative reactions.

On the other hand, the decrease in total organic acid concentrations between AMPc and AMP-LM1 suggests that organic acids may have been effectively adsorbed to shale organic matter (Figure 3). This is supported by the increase in TOC content on the AMP-LM1 reacted shale sample. Strong oxidizing agents may proliferate organic acids; however, future studies need to constrain the sources of organic acids in shale organic matter (e.g., bitumen and kerogen).

The high TOC content of the LM1 shale sample may provide absorption sights for organic compounds within the organic matrix of kerogen. As shales increase in maturity, the organic matrix becomes aromatic in structure which increases surface area and porosity (Zargari et al., 2015, Zhang et al., 2013, Pilewski et al., 2019). Differences in the organic matter matrix corresponding to different thermal maturity may allow organic compounds to be absorbed and trapped within the kerogen of the shale. Organic compounds liberated from shale due to hydraulic fracturing operations, or the organic additives in HFF, would be effectively adsorbed 
by this process. This may explain the decrease in NPOC in AMP-LM1 and SB-LM1 and the increase in shale TOC associated with AMP-LM1 (Figure 3).

Additionally, studies have shown that low $\mathrm{pH}$ aqueous systems may prevent organic matter desorption from acid-resistant mineral surfaces such as quartz, inhibiting organic matter oxidation (Jing et al., 2018; Mikutta et al., 2005). This may further support the liberation of organic acids in SB-LM1 but the low $\mathrm{pH}$ environment would inhibit further organic acid proliferation and effectively adsorb them back to the shale organic matter. Previous studies have observed similar trends during bench top fluid-shale reactions (Pilewski et al., 2019, Marcon et al., 2017, Tasker et al., 2016). The increase of NPOC in SH-LM1 and decrease in shale TOC, suggests sodium hypochlorite has high reactivity with shale organic matter. This resulted in the extensive degradation of shale organic matter and the release of NPOC. These results show the affinity of oxidative breakers for organic matter dissolution during fluid-shale reactions.

\section{Effect of breakers on Critical Mineral Mobility}

The variation in critical mineral distribution in our shale reacted effluents suggests their mobility was influenced by the interaction with the different oxidative HFF solutions. Our results show that shale reacted effluents with the highest initial ORP produced the highest concentration of dissolved critical minerals (Figure 4, Figure 5, Figure 6, Figure 7). Critical mineral concentrations are $439 \%$ and $408 \%$ higher in SB-LM1 and SH-LM1 respectively, compared to AMP-LM1. The liberation of metals and metalloids into solution is commonly associated with the degradation of organic matter and pyrite through oxidative dissolution (Phan et al., 2015, Wang et al., 2015). Organic matter and pyrite become unstable in oxidizing and low $\mathrm{pH}$ conditions which may release bound trace elements such as $\mathrm{Fe}, \mathrm{Se}, \mathrm{As}, \mathrm{Cd}, \mathrm{Cu}, \mathrm{Pb}, \mathrm{Zn}$, and $\mathrm{Tl}$ (Dang et al., 2002, Baruah et al., 2010, Xiao et al., 2012). However, our data suggests that it does 
not support the hypothesis that low $\mathrm{pH}$ conditions are a primary control on the mobility of critical minerals and metals. Particularly, $\mathrm{Pb}$ is primarily associated with pyrite in shales and can be released upon dissolution (Rimstidt and Vaughan, 2003). The highest Pb concentrations were observed in SB-LM1 and SH-LM1, where a decrease in pyrite was also noted by XRD analysis. However, complete dissolution of pyrite was observed in SB-LM1, but Pb concentrations were over sixty-five percent lower in SB-LM1 (10.1 ug/l) than in SH-LM1 (29.5 ug/l). This suggests that the mobility of $\mathrm{Pb}$ may be largely controlled by organic matter degradation instead of pyrite dissolution.

Enhancement of critical mineral mobility via pyrite dissolution may be explained by the increased concentrations of $\mathrm{As}, \mathrm{Cu}, \mathrm{Cd}$, and $\mathrm{Zn}$ that followed the same trend in SB-LM1 and SHLM1. In addition, breakers ammonium persulfate and sodium bromate have been observed to alter the chemio-physical characteristics of kerogen in shale samples (Hull et al., 2019). Fluidkerogen experiments with Marcellus Shale samples have been noted to release Fe, S, Co, Ni, and $\mathrm{Pb}$ (Dustin et al., 2018). Likely, the release of a portion of these metals in the shale effluents is from the degradation of kerogen. However, to constrain the effect of oxidizers on kerogen degradation, future studies are needed to isolate their interactions. Additionally, this may provide insight into the source of other trace elements observed in our effluents such as $\mathrm{V}, \mathrm{Cr}, \mathrm{Pb}, \mathrm{Ti}$ and U.

As described above, oxidative fluids effectively enhance critical mineral mobility through the presumed oxidative transformation of shale organic matter and mineral content. Our data suggest that element mobility is enhanced by the selectivity of different breakers. This is apparent in the significantly higher concentrations of trace elements observed in SB-LM1 and SH-LM1 relative to AMP-LM1 (Table S4). The extent of critical mineral mobility may be 
explained by the limitations of the individual breakers. Ammonium persulfate forms a free radical sulfate during decomposition (Liang et al., 2018). It is likely the complete consumption of these free radicals occurred by reaction with other HFF components and may have limited the oxidizing capacity of ammonium persulfate.

Additionally, sulfate derived from persulfate reduction may be a source for sulfate scales such as barite. Barite precipitation was observed in AMP-LM1 and potentially acted as a sink for sulfate radicals, therefore inhibiting the reactivity of ammonium persulfate. This could also create problematic scales in fracture zones or the wellbore during fracturing operations. On the other hand, sodium bromate has been noted to perform well at elevated temperatures (Hull et al., 2019) and likely was active for a longer period of time during fluid-shale contact. This would effectively allow shale organic matter to be oxidized to a further extent and potentially release higher concentrations of critical minerals into solution. Similarly, sodium hypochlorite was observed to have an affinity for interacting with shale organic matter that was observed in the pronounced decrease of LM1 TOC content. This implies that the degradation of shale organic matter could have readily leached high concentration of trace elements. Our results show that contaminant mobility is related to the organic and mineral phases of shale and is enhanced by the presence of specific oxidative breakers in HFF.

The demand for critical element recovery and extraction has increased in recent years. The geochemical data of our samples indicates the potential for oxidative breakers to release significant concentrations of trace and critical elements during shale-fracturing operations. Although the presence of critical minerals in produced waters may give rise to environmental concerns, the importance that the recovery of these elements and metals may become viable 
should be considered. Further studies are needed to assess the use of oxidative breakers on understanding the recovery of critical minerals during shale-gas operations.

\section{Effect of breakers on Mineralogy and Major Ions}

The initial low $\mathrm{pH}$ of AMPc and SBc is comparable to the $\mathrm{pH}$ of HFF's used in the Marcellus Shale (Jew et al., 2018). All control fluids contained hydrochloric acid (HCl), an additive used to prevent mineral scaling in the wellbore and is likely responsible for the low $\mathrm{pH}$ observed in the control fluids. On the other hand, SHc had an initially high $\mathrm{pH}$ due to the basic nature of sodium hypochlorite as an oxidative breaker. The increase in $\mathrm{pH}$ of shale reacted effluent samples can result from alkalinity generated by carbonate mineral dissolution (Vankeuren et al., 2017, Harrison et al., 2017). The pH increased to 5.74 and 3.76 in AMP-LM1 and SB-LM1 respectively, and suggests carbonate minerals provided buffering capacity. This is supported by the increase in dissolved inorganic carbon (DIC) concentration in the shale reacted effluents and an apparent decrease in carbonate mineral content shown by XRD. DIC and $\mathrm{pH}$ of effluents were highest in samples where carbonate mineral content decreased the most. In SBLM1, the $\mathrm{pH}$ remained relativity low even though total consumption of carbonate minerals was observed in that sample (Figure 8). This may be partly due to the high concentration of trace elements and metals in solution (Figure 5 and Table S4) that would increase acidity and lower the buffering capacity (Harrison et al., 2017, Dustin et al., 2018). AMP-LM1 contained a negligible amount of trace metals in solution and any acidity generated would be insufficient to counterbalance any alkalinity generated by carbonate dissolution.

Additionally, the $\mathrm{pH}$ of SH-LM1 was likely influenced by the high concentration of the weak base sodium hypochlorite added as a breaker. Therefore, the real impact of carbonate dissolution and trace element influence in this sample cannot be determined. These observations 
suggest that carbonate mineral dissolution, trace metal concentrations, and HFF chemistry influenced the $\mathrm{pH}$ of the shale reacted effluents.

The higher concentrations of sulfate in post-reacted fluids compared to the control fluids indicates that the oxidative dissolution of sulfate bearing minerals such as pyrite and marcasite on reaction with HFF might be responsible for sulfate generation (Figure 9). This hypothesis is supported by the fact that the highest concentrations of sulfate were detected in SB-LM1 and SH-LM1 effluents and XRD analysis of both these samples indicate a significant decline in pyrite and marcasite composition (Figure 9). The highest concentration of sulfate observed in SB-LM1 combined with total consumption of sulfate bearing minerals during the experiment, suggests an affinity for the oxidation of these minerals by sodium bromate. AMP-LM1 also showed an increase in sulfate concentrations from $478.9 \mathrm{mg} / \mathrm{l}$ to $602.9 \mathrm{mg} / \mathrm{l}$ however, the XRD data does not indicate any change in sulfur-bearing mineral content. Therefore, an increase in sulfate concentration in AMP-LM1 effluent is attributed to the degradation of ammonium persulfate because sulfate free-radicals are generated by ammonium persulfate at elevated temperatures (Liang et al., 2018).

Sulfate generated by pyrite and marcasite dissolution in the effluent samples can stimulate the precipitation of minerals such as barite and gypsum (Chen et al., 2018, Vankeuren et al., 2017). We note a decline in Ba concentrations in all shale reacted effluents with the abundance of sulfate ions. This is attributed to the reaction of $\mathrm{Ba}$ and sulfate ions resulting in the precipitation of barite. XRD analysis shows barite content increased the most in AMP-LM1, followed by SH-LM1 and SB-LM1 (Figure 8). Our results are similar to previous fluid-shale studies that have observed barite precipitation (Pilewski et al., 2019, Vankeuren et al., 2017, Xiong et al., 2020). Additionally, the presence of organic acids has been associated with 
increased concentrations of $\mathrm{Ba}$ and sulfate in produced waters (He et al., 2014). However, organic acids can affect the solubility of scaling minerals such as barite, through the removal of cations in solution by complex formation with organic acids (Hakala et al., 2017). This may have limited the precipitation of barite to occur. Similarly, gypsum was only observed in SB-LM1 and SH-LM1. The abundance of Ca and sulfate ions in SB-LM1 and SH-LM1 were likely available to allow the secondary precipitation of gypsum. In the case of AMP-LM1, the absence of gypsum is likely due to an insufficient amount of available sulfate ions. This could be due to the lack of sulfate ions that would have been generated by the dissolution of pyrite and marcasite, or an inadequate amount of sulfate remained after the precipitation of barite. On the other hand, halite was exclusively observed in SH-LM1. The highest concentrations of chloride were observed in SH-LM1 and may have resulted from the thermal breakdown of sodium hypochlorite. An abundance of chloride ions may have been generated by this process and could effectively react with $\mathrm{Na}$ in solution to form halite. Our results suggests that the precipitation of these minerals occurs in shales and is governed by ions in solution from HFF additives and the shale mineralogy (Figure 9).

The increase in phosphate concentrations in the shale-reacted effluents cannot be attributed to the oxidative breakers utilized during this study. This implies the source of phosphate is potentially from phosphate-bearing mineral phases such as apatite within the shale sample. The increase in DIC of shale reacted effluents, trace amounts of $\mathrm{F}$ - and increase in $\mathrm{Ca}$ concentrations may be further evidence for apatite dissolution. Apatite was not detected in the $\mathrm{XRD}$ analysis; however, the presence of apatite in trace amounts should be considered as a potential contributor the net fluid-rock interactions. 


\subsection{Conclusions:}

Fluid-shale experiments were conducted using oxidizing HFF, that were created using common industry breakers: ammonium persulfate, sodium bromate, and sodium hypochlorite. The experiments were carried out at formation temperature to investigate contaminant and critical mineral release, along with changes in major ion chemistry and mineralogy. Our study illustrates that the type of oxidative breaker used during HFF operations may control many of the reactions that occur during fluid-shale interaction and the results demonstrate that:

1. The type and amount of VOCs and SVOCs produced in control fluids and shale reacted effluents is strongly dictated by the oxidative breaker. Organic compounds were found to be generated by the transformation of additives within the HFF and by the degradation of shale organic matter. Additionally, the presence of halogenated VOCs was greatest in reactions with sodium bromate and sodium hypochlorite and lowest with ammonium persulfate.

2. Organic acids were ubiquitous in control and shale reacted effluents. However, concentrations of organic acids increased in shale reacted effluents with the highest ORP. The decrease in organic acids in AMP-LM1 can be attributed to adsorption to organic matter, shown by a reduction in NPOC and increase in TOC content.

3. Shale organic matter and unstable constituents such as pyrite were subject to oxidation by each HFF solution. Organic matter degradation occurred to the greatest extent in SHLM1 and indicates an affinity for sodium hypochlorite. SB-LM1 was most effective at oxidizing pyrite and is shown by the total consumption of iron-sulfate minerals. Organic matter was least impacted by ammonium persulfate and is indicated by the decrease in NPOC and increase in TOC of AMP-LM1. 
4. The oxidation of organic matter and shale constituents would release critical minerals such as various metals and metalloids into solution. Critical mineral mobility was governed primarily by HFF ORP.

5. Oxidants in HFF could result in complex fluid-rock interactions that could stimulate secondary mineral precipitation and dissolution. Reactions were controlled by carbonate mineral dissolution, and secondary precipitation of barite, gypsum, and halite. Sulfate ions in solution resulting from enhanced pyrite oxidation and oxidant degradation of ammonium persulfate could result in the generation of barite and gypsum. The degradation of sodium hypochlorite may promote the precipitation of halite.

Our experiments confirm that the type of oxidant added to HFF can influence many reactions during fluid-shale interaction. Further studies are needed to investigate organic contaminant transformation pathways and rates of critical mineral mobility by oxidizing agents. Further studies are also needed to assess the use of oxidative breakers on understanding the recovery of critical elements during shale-gas operations. A better understanding of these geochemical reactions is needed to mitigate environmental hazards that may be associated with field scale use of oxidizing fluids in hydraulic fracturing operations.

\subsection{Acknowledgements:}

This research was funded by the Department of Energy's National Energy Technology Laboratory (DOE-NETL) grants DE\#FE0024297 and DE\#FE0004000.

\subsection{Conclusion:}

In this study, we conducted laboratory scale fluid-rock interactions mimicking reservoir temperatures and for a duration in accordance with the typical shut-in period ( 2 weeks) of a 
hydraulic fracturing operation. Our experiments comprised of three oxidative HFF solutions that were comprised of common industry breakers ammonium persulfate, sodium bromate, and sodium hypochlorite. To identify geochemical processes influenced by oxidative breakers, we focused analyses on the presence of organic compounds, critical minerals such as metals and metalloids, mineralogy, and major ion chemistry. The results showed that the oxidant used in each HFF controlled the type and amount of VOCs and SVOCs present in control and shale reacted effluents. Organic compounds were found to be governed by the oxidative strength of the HFF, in which solutions with the highest ORP produced the largest quantities of VOCs. Additionally, organic compounds were found to be generated by the transformation of additives within the HFF and by the degradation of shale organic matter. Effluent samples also showed that addition of oxidants sodium bromate and sodium hypochlorite, promoted the halogenation of many organic compounds. Organic acids were observed to be ubiquitous in control and shale reacted effluents, suggesting a portion of the total organic acids may be sourced from the transformation of HFF additives. However, concentrations of organic acids increased in shale reacted effluents SB-LM1 and SH-LM1 likely by the degradation of shale organic matter and decreased in AMP-LM1 due to the potential absorption to shale organic matter. Shale organic matter and unstable constituents such as pyrite were subject to oxidation by each HFF solution and resulted in the release of critical minerals into solution. Metals and metalloids including Be, $\mathrm{Co}, \mathrm{Mo}, \mathrm{Ag}, \mathrm{Cd}, \mathrm{Sb}, \mathrm{Tl}$, and $\mathrm{U}$ were only present in shale reacted effluents and indicates leaching from the shale. Critical mineral mobility occurred to the greatest extent where HFF ORP was the highest. Moreover, oxidants in HFF could result in complex fluid-rock interactions that could stimulate secondary mineral precipitation and dissolution. Reactions were controlled by carbonate mineral dissolution, and secondary precipitation of barite, gypsum, and halite. 
Sulfate ions in solution resulted from the enhanced oxidation of pyrite and from the degradation of ammonium persulfate and could result in the generation of barite and gypsum. The degradation of sodium hypochlorite may promote the precipitation of halite. Further studies are needed to constrain the source and transformation of organic compounds produced by oxidative dissolution. Additionally, future studies are needed to characterize how kerogen may be directly impacted by oxidative dissolution including the contribution of trace element, metal, and contaminant concentrations. 


\subsection{References:}

Agrawal V. and Sharma S. 2018. Improved Kerogen models for determining hydrocarbon potential and thermal maturity of shales. Nature Scientific Reports 8: 17465

Agrawal, V. and Sharma, S. 2017. Molecular Characterization of Kerogen from Marcellus Shale and its Implications for determining sources of organic matter, hydrocarbon Potential and thermal Maturity. Fuel

Bank T., Malizia T., and Andresky L. 2010. Uranium geochemistry in the Marcellus shale Effects on metal mobilization. GSA 2010 Denver Annual Meeting

Barati, R., and Liang, J., 2014. A Review of Fracturing Fluid Systems Used For Hydraulic Fracturing of Oil and Gas Wells: Journal of Applied Polymer Science, v. 131, doi:10.1002/app.40735.

Barati, R., Hutchins, R. D., Friedel, T., Ayoub, J. A., Dessinges, M. N., and England, K. W. 2009. Fracture impact of yield stress and fracture-face damage on production with a three-phase 2D model. SPE production \& operations, 24(02), 336-345.

Baruah, B.P., Khare, P., 2010. Mobility of trace and potentially harmful elements in the environment from high sulfur Indian coal mines. Appl. Geochem. 25, 1621-1631. https://doi.org/10.1016/j.apgeochem.2010.08.010.

Bazant, Z.P., Salviato, M., Chau, V.T., Viswanathan, H., and Zubelewicz, A., 2014, Why Fracking Works: JOURNAL OF APPLIED MECHANICS-TRANSACTIONS OF THE ASME, v. 81, doi:10.1115/1.4028192

Bekki K., Toriba A., Tang N., Kameda T., Hayakawa K. 2013. Biological effects of polycyclic aromatic hydrocarbon derivatives. J. UOEH. 2013;35:17-24. doi: 10.7888/juoeh.35.17.

Brantley, S.L., Yoxtheimer, D., Arjmand, S., Grieve, P., Vidic, R., Pollak, J., Llewellyn, G.T., Abad, J., and Simon, C., 2014, Water resource impacts during unconventional shale gas development: The Pennsylvania experience: Environmental geology and the unconventional gas revolution, v. 126, p. 140-156, doi:10.1016/j.coal.2013.12.017.

Butkovskyi, A., Bruning, H., Kools, S., Rijnaarts, H., Van Wezel, A.P. 2017. Environmental Science \& Technology 51(9),4740-4754DOI:10.1021/acs.est.6b05640

Chen, Q., Kang, Y., You, L., Yang, P., Zhang, X., and Cheng, Q., 2017, Change in composition and pore structure of Longmaxi black shale during oxidative dissolution: International Journal of Coal Geology, v. 172, p. 95-111, doi:10.1016/j.coal.2017.01.011.

Clark, C.E., and Veil, J.A., 2009. Environmental SD, Produced Water Volumes and Management Practices in the United States, UNT Digital Library. Argonne National Laboratory, 2009, https://digital.library.unt.edu/ark:/67531/metadc836481/

Cluff, M.A., Hartsock, A., MacRae, J.D., Carter, K., Mouser, P.J., 2014. Temporal Changes in 734 Microbial Ecology and Geochemistry in Produced Water from Hydraulically Fractured 735 Marcellus Shale Gas Well 
Cluff, M.A., Hartsock, A., MacRae, J.D., Carter, K., Mouser, P.J., 2014.Temporal changes inmicrobial ecology and geochemistry in produced water from hydraulically fracturedMarcellus Shale gas wells. Environ. Sci. Technol. 48, 6508-6517.

Dang, Z., Liu, C., Haigh, M.J., 2002. Mobility of heavy metals associated with the natural weathering of coal mine spoils. Environ. Pollut. 118, 419-426. https://doi.org/10. 1016/S0269-7491(01)00285-8.

Dayan, A., Stracener, S. M., \& Clark, P. E. 2009. Proppant transport in slickwater fracturing of shale gas formations. In SPE Annual Technical Conference and Exhibition. Society of Petroleum Engineers.

Dustin, M. K., Bargar, J. R., Jew, A. D., Harrison, A. L., Joe-Wong, C., Thomas, D. L., and Maher, K. 2018. Shale kerogen: hydraulic fracturing fluid interactions and contaminant release. Energy \& fuels, 32(9), 8966-8977.

Economides, M. J., and Nolte, K. G. 1989. Reservoir stimulation (Vol. 2). Englewood Cliffs, NJ: Prentice Hall.

Elsner, M., and Hoelzer, K., 2016, Quantitative Survey and Structural Classification of Hydraulic Fracturing Chemicals Reported in Unconventional Gas Production: Environmental Science \& Technology, v. 50, p. 3290-3314, doi:10.1021/acs.est.5b02818.

FracFocus Chemical Disclosure Registry, Ground Water Protection Council and Interstate Oil and Gas Compact Commission, 2016, (http://fracfocus.org).

Gregory K. B, Vidic R.D., and Dzombak D.A., Water Management Challenges Associated with the Production of Shale Gas by Hydraulic Fracturing, Elements, 2011,7(3),181-186.

Guerra, K., Dahm, K., and Dundorf, S., 2011. Oil and gas produced water management and beneficial use in the Western United States, US Department of the Interior, Bureau of Reclamation, 2011.

Hakala, J. A., Phan, T., Stuckman, M., Edenborn, H., and Christina L., 2017 "Role of Organic Acids in Controlling Mineral Scale Formation During Hydraulic Fracturing at the Marcellus Shale Energy and Environmental Laboratory (MSEEL) Site." Paper presented at the SPE/AAPG/SEG Unconventional Resources Technology Conference, Austin, Texas, USA, July 2017. doi: https://doi.org/10.15530/URTEC-2017-2670833

Harrison, A. L., Jew, A. D., Dustin, M. K., Thomas, D. L., Joe-Wong, C. M., Bargar, J. R., and Maher, K. 2017. Element release and reaction-induced porosity alteration during shalehydraulic fracturing fluid interactions. Applied Geochemistry, 82, 47-62.

Hawboldt, K. and Adams, S., 2005. "A comparison of PAHs in produced water discharges and flared gas emissions to the ocean," Proceedings of OCEANS 2005 MTS/IEEE, Washington, DC, USA, 2005, pp. 2217-2223 Vol. 3, doi:

10.1109/OCEANS.2005.1640095 
He, C., Meng, L., Wenshi, L., Barbot, E., Vidic, R., 2014. Kinetics and Equilibrium of Barium and Strontium Sulfate Formation in Marcellus Shale Flowback Water. Journal of Environmental Engineering. 140. 10.1061/(ASCE)EE.1943-7870.0000807.

Hoelzer, K., Sumner, A. J., Karatum, O., Nelson, R. K., Drollette, B. D., O’Connor, M. P.,Plata, D. L. 2016. Indications of Transformation Products from Hydraulic Fracturing Additives in Shale-Gas Wastewater. Environmental Science \& Technology,50(15), 8036-8048. doi:10.1021/acs.est.6b00430

Hull, K.L., Jacobi, D., and Abousleiman, Y.N., 2019, Oxidative Kerogen Degradation: A Potential Approach to Hydraulic Fracturing in Unconventionals: ENERGY \& FUELS, v. 33, p. 4758-4766, doi:10.1021/acs.energyfuels.9b00104.

Jew, A. D., Dustin, M. K., Harrison, A. L., Joe-Wong, C. M., Thomas, D. L., Maher, K.,Bargar, J. R. 2017. Impact of Organics and Carbonates on the Oxidation and Precipitation of Iron during Hydraulic Fracturing of Shale. Energy \& Fuels,31(4), 3643-3658. doi:10.1021/acs.energyfuels.6b03220

Kahrilas, G. A.; Blotevogel, J.; Stewart, P. S.; Borch, T. 2015 Biocides in hydraulic fracturing fluids: A critical review of their usage, mobility, degradation, and toxicity. Environ. Sci. Technol. 2015, 49 (1), 16-32.

Kondash, A., and Vengosh, A., 2015, Water Footprint of Hydraulic Fracturing: Environmental Science \& Technology Letters, v. 2, p. 276-280, doi:10.1021/acs.estlett.5b00211.

Lewis, R. J., \& Sax, N. I. 2004. Sax's dangerous properties of industrial materials (11th ed.). J. Wiley \& Sons

Liang, C., Huang, C.-F., and Chen, Y.-J., 2008, Potential for activated persulfate degradation of BTEX contamination: Water Research, v. 42, p. 4091-4100, doi:10.1016/j.watres.2008.06.022.

Luek, J.L., Gonsior, M. 2017. A Review of Organic Compounds in Hydraulic Fracturing Fluids and Wastewaters. Water Research 123, 536-548. DOI:10.1016/j.watres.2017.07.012

Marcon, V., Joseph, C., Carter, K.E., Hedges, S.W., Lopano, C.L., Guthrie, G.D., and Hakala, J.A., 2017, Experimental insights into geochemical changes in hydraulically fractured Marcellus Shale: APPLIED GEOCHEMISTRY, v. 76, p. 36-50, doi:10.1016/j.apgeochem.2016.11.005.

Montgomery, C. T., \& Smith, M. B. (2010). Hydraulic fracturing: history of an enduring technology. Journal of Petroleum Technology, 62(12), 26-40.

Müller, V. 2001. Bacterial Fermentation. In eLS,(Ed.). https://doi.org/10.1038/npg.els.0001415

Murali Mohan, A., Hartsock, A., Hammack, R.W., Vidic, R.D., Gregory, K.B., 2013. Microbial 907 communities in flowback water impoundments from hydraulic fracturing for recovery of 908 shale gas. FEMS Microbiol. Ecol. 86, 567-580. doi:10.1111/15746941.12183 
Phan, T.T., Capo, R.C., Stewart, B.W., Graney, J.R., Johnson, J.D., Sharma, S., Toro, J., 2015.Trace metal distribution and mobility in drill cuttings and produced waters fromMarcellus Shale gas extraction: uranium, arsenic, barium. Appl. Geochem. 60,89103.

Pilewski, J., Sharma, S., Agrawal, V., Hakala, J.A., and Stuckman, M.Y., 2019, Effect of maturity and mineralogy on fluid-rock reactions in the Marcellus Shale: Environmental Science: Processes \& Impacts, v. 21, p. 845-855, doi:10.1039/C8EM00452H.

Qiang Chen, Lijun You, Yili Kang, Liandong Dou, and James J. Sheng 2018. Energy \& Fuels 201832 (10), 10367-10381 DOI: 10.1021/acs.energyfuels.8b01711

Rimstidt, J.D. and Vaughan, D.J. 2003, "Pyrite oxidation: A state-of-the-art assessment of the reaction mechanism", Geochimica et Cosmochimica Acta, vol. 67, no. 5, pp. 873-880.

Rowan, E.L., Engle, M.A., Kraemer, T.F., Schroeder, K.T., Hammack, R.W., Doughten,M.W., 2015.Geochemical and isotopic evolution of water produced from MiddleDevonian Marcellus Shale gas wells, Appalachian Basin, Pennsylvania. AAPG Bull.99, 181-206

Rozell, D.J., and Reaven, S.J., 2012, Water Pollution Risk Associated with Natural Gas Extraction from the Marcellus Shale.: Risk Analysis: An International Journal, v. 32, p. 1382-1393.

Sharma S., Agrawal V., Akondi R., Wang Y., and Hakala J. A., Environ. Sci.: Processes Impacts, 2021, DOI:10.1039/D0EM00388C.

Sifniades, S., Levy, A.B. and Bahl, H. 2011. Acetone. In Ullmann's Encyclopedia of Industrial Chemistry, (Ed.). https://doi.org/10.1002/14356007.a01_079.pub3

Soni V., Singh P., Shree V., Goel V. 2018 Effects of VOCs on Human Health. In: Sharma N., Agarwal A., Eastwood P., Gupta T., Singh A. (eds) Air Pollution and Control. Energy, Environment, and Sustainability. Springer, Singapore. https://doi.org/10.1007/978-981$\underline{10-7185-0 \_8}$

Strong, L. C., Gould, T., Kasinkas, L., Sadowsky, M. J., Aksan, A., \& Wackett, L. P. 2014. Biodegradation in Waters from Hydraulic Fracturing: Chemistry, Microbiology, and Engineering. Journal of Environmental Engineering,140(5). doi:10.1061/(asce)ee.19437870.0000792

Sumner, A.J., and Plate, D.L., 2019, Oxidative Breakers Can Stimulate Halogenation and Competitive Oxidation in Guar-Gelled Hydraulic Fracturing Fluids: ENVIRONMENTAL SCIENCE \& TECHNOLOGY, v. 53, p. 8216-8226, doi:10.1021/acs.est.9b01896.

Tasker, T., Piotrowski, P.K., Dorman, F.L., and Burogs, W.D., 2016. Environmental Engineering Science. Oct 2016. 753-765. Doi.org/10.1089/ees.2015.0605

U.S. EIA, Updates to the Marcellus Shale Play Maps, U.S. EIA, 2019, 14. 
U.S. EPA. Drinking Water Criteria Document for Polycyclic Aromatic Hydrocarbons (PAH) (Final Draft, 1985). U.S. Environmental Protection Agency, Washington, D.C., ECAOCIN-D010 (NTIS PB86117801), 1991

US Energy Information Administration (2018) Annual Energy Outlook, Energy Information Administration. Available at: https://www.eia.gov/outlooks/aeo/ [Accessed April 3, 2021].

Vankeuren, A.N.P., Hakala, J.A., Jarvis, K., and Moore, J.E., 2017, Mineral Reactions in Shale Gas Reservoirs: Barite Scale Formation from Reusing Produced Water As Hydraulic Fracturing Fluid: ENVIRONMENTAL SCIENCE \& TECHNOLOGY, v. 51, p. 93919402, doi:10.1021/acs.est.7b01979.

Wang L., Fortner J.D., and Giammar D.E. 2015. Impact of Water Chemistry on Element Mobilization from Eagle Ford Shale. Environ. Eng. Sci. 32, 310

Welch S.A, Sheets J.M, Daly R.A., Hanson A., Sharma S., Darrah T., Olesik J., Lutton A., Mouser P.J., Wrighton K.C., Wilkins M.J., Carr T., Cole D.R., Comparative geochemistry of flowback chemistry from the Utica/Point Pleasant and Marcellus formations, Chemical Geology

Wilke, F.D.H., Vieth-Hillebrand, A., Naumann, R., Erzinger, J., Horsfield, B., 2015. Induced mobility of inorganic and organic solutes from black shales using water extraction: Implications for shale gas exploitation. Applied Geochemistry 63, 158-168.

Xiao, T., Yang, F., Li, S., Zheng, B., Ning, Z., 2012. Thallium pollution in China: a geoenvironmental perspective. Sci. Total Environ. 421-422, 51-58. https://doi.org/10. 1016/j.scitotenv.2011.04.008.

Xiong, W., Gill, M., Moore, J., Crandall, D., Hakala, A., and Lopano, C., 2020. Energy \& Fuels 202034 (11), 13625-13635 DOI: 10.1021/acs.energyfuels.0c02156

You, L., Kang, Y., Chen, Q., Fang, C., and Yang, P., 2017, Prospect of shale gas recovery enhancement by oxidation-induced rock burst: Natural Gas Industry B, v. 4, p. 449-456, doi:10.1016/j.ngib.2017.05.014.

Zagorski, W A., Emery, M., and Ventura, J., 2017, The Marcellus Shale Play: Its Discovery and Emergence as a Major Global Hydrocarbon Accumulation, in R. K. Merrill and C. A. Sternbach, eds., Giant fields of the decade 2000-2010: AAPG Memoir 113, p. 55-90.

Zargari, S., Canter, K. L., \& Prasad, M. 2015. Porosity evolution in oil-prone source rocks. Fuel, 153, 110-117. https://doi.org/10.1016/j.fuel.2015.02.072

Zhang, B.; Huston, A.; Whipple, L.; Barrett, H.; Wall, M.;Hutchins, R.; Mirakyan, A. SPE Production Operat. 2013, 28, 210.

Ziemkiewicz, P.F., and He, Y.T., 2015, Evolution of water chemistry during Marcellus Shale gas development: A case study in West Virginia: CHEMOSPHERE, v. 134, p. 224-231, doi:10.1016/j.chemosphere.2015.04.040. 


\subsection{Figures}

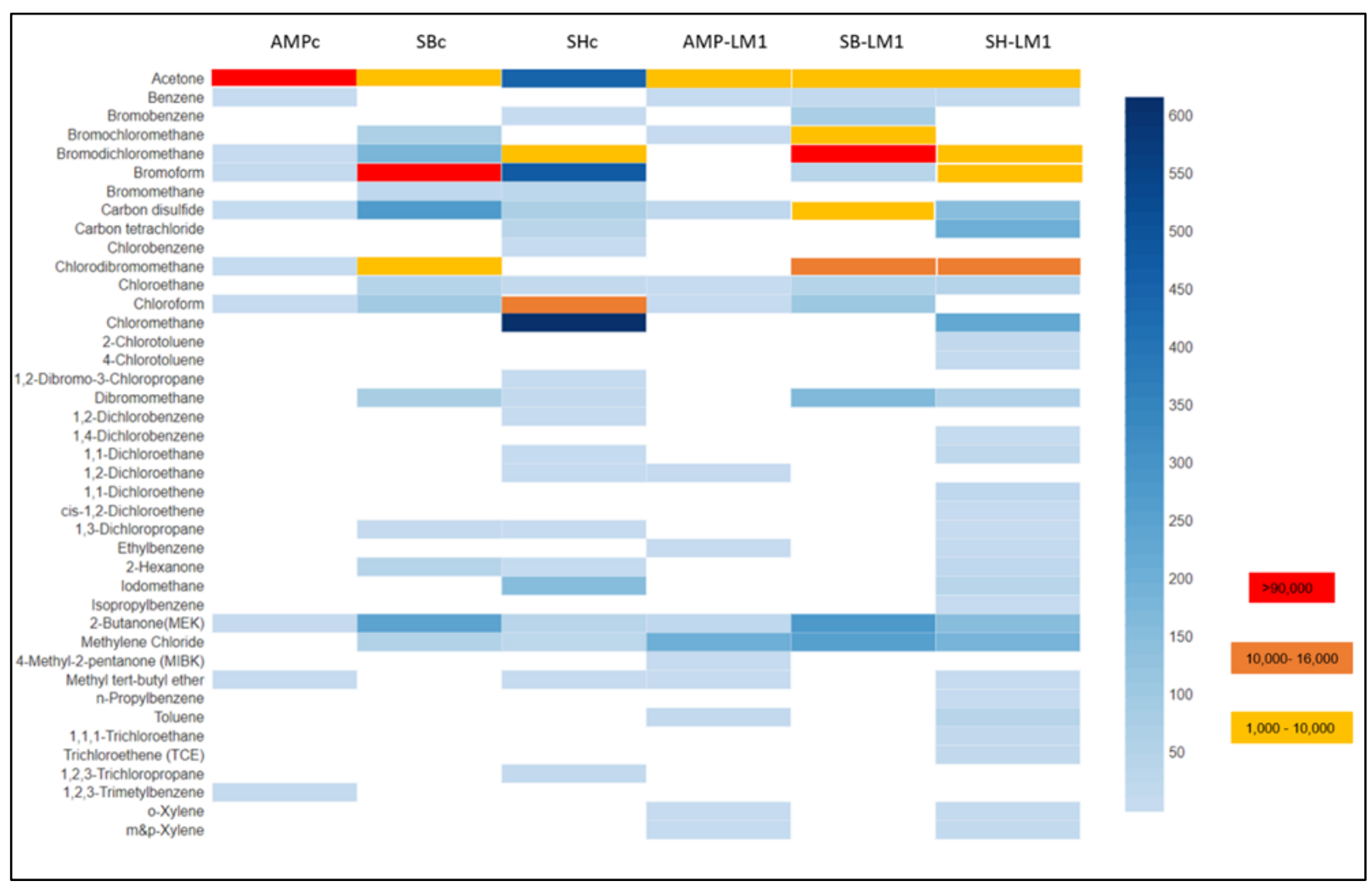

Figure 1: Heat map summarizing all VOCs observed in effluent samples. Low concentration VOCs are represented by the increasing blue scale and higher concentration VOCs are represented by yellow, orange, and red respectively. Concentrations are reported in ug/L. 


\section{Total VOC and ORP}

140000

1200

Ð 120000

일

드 100000

苋 80000

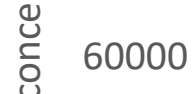

९ 40000

乓 20000

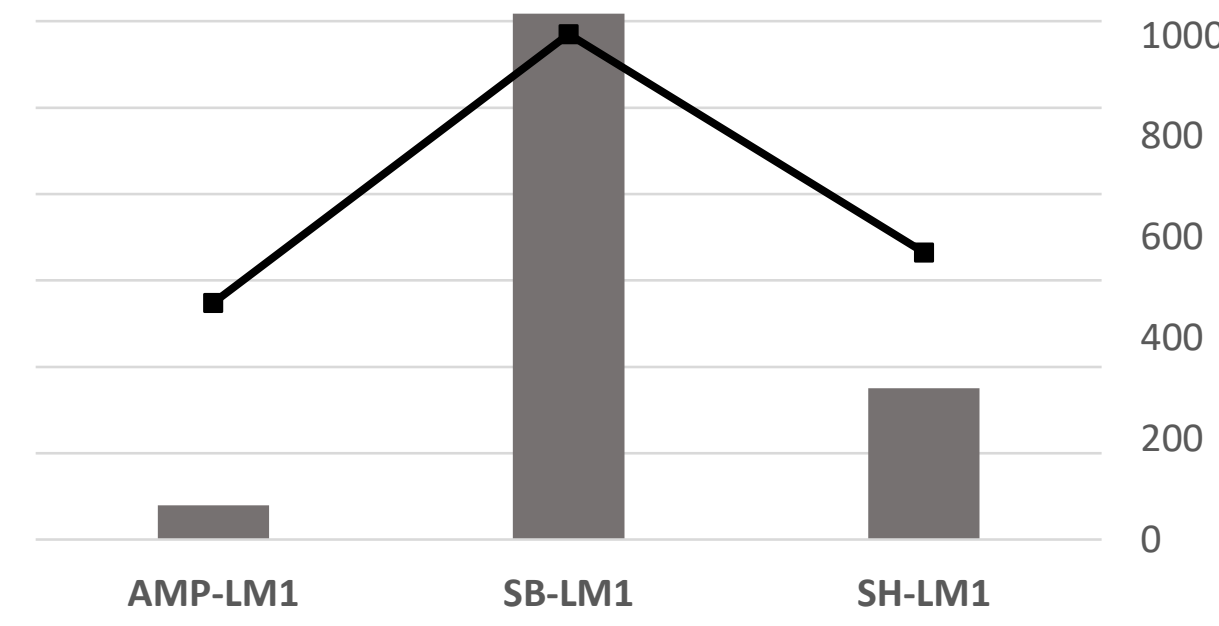

Total VOC

$\rightarrow$ ORP

Figure 2: Total VOC concentration in shale reacted effluents with respect to the initial ORP of the HFF solution.

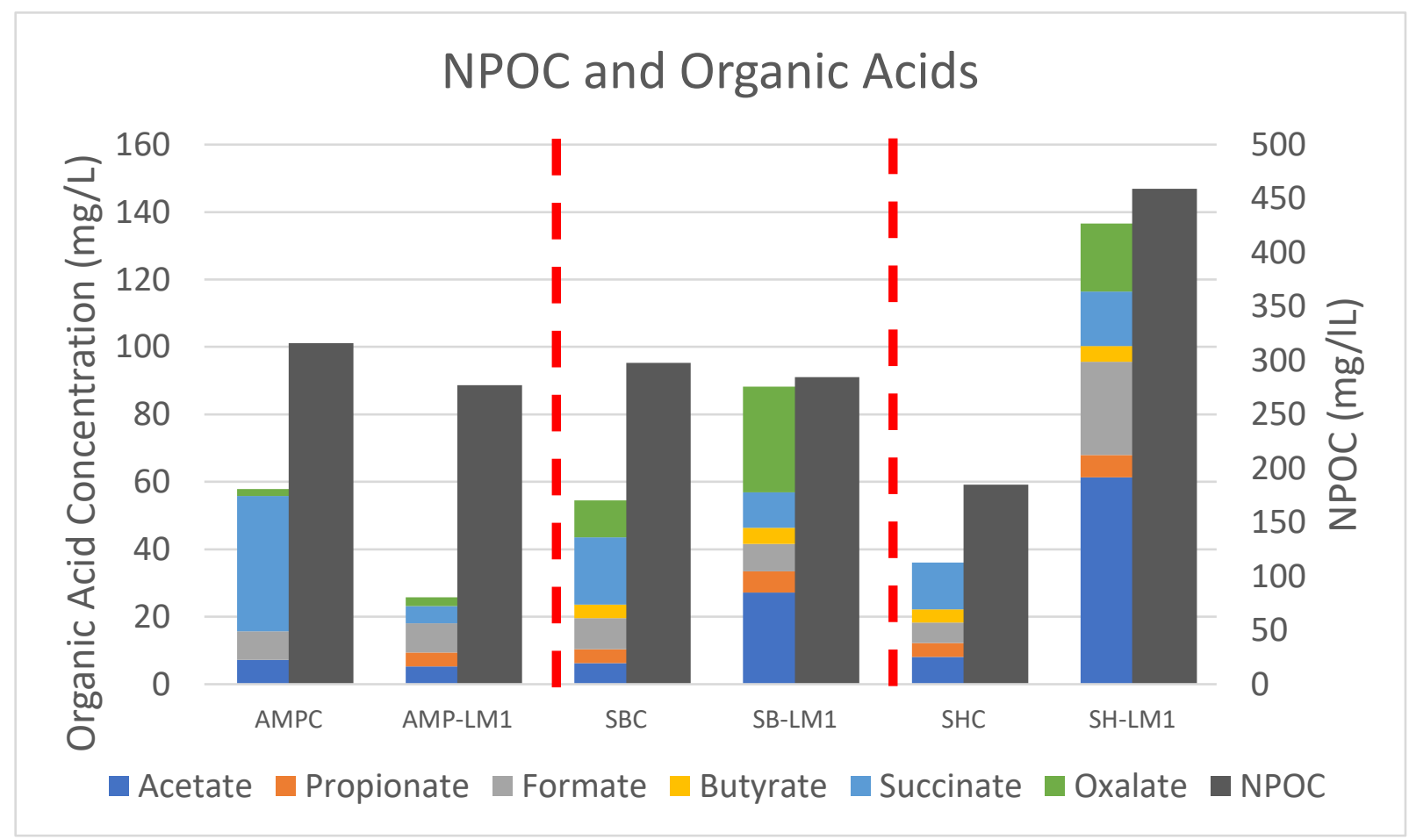

Figure 3: Organic acid and NPOC concentrations of control and shale reacted effluents. 


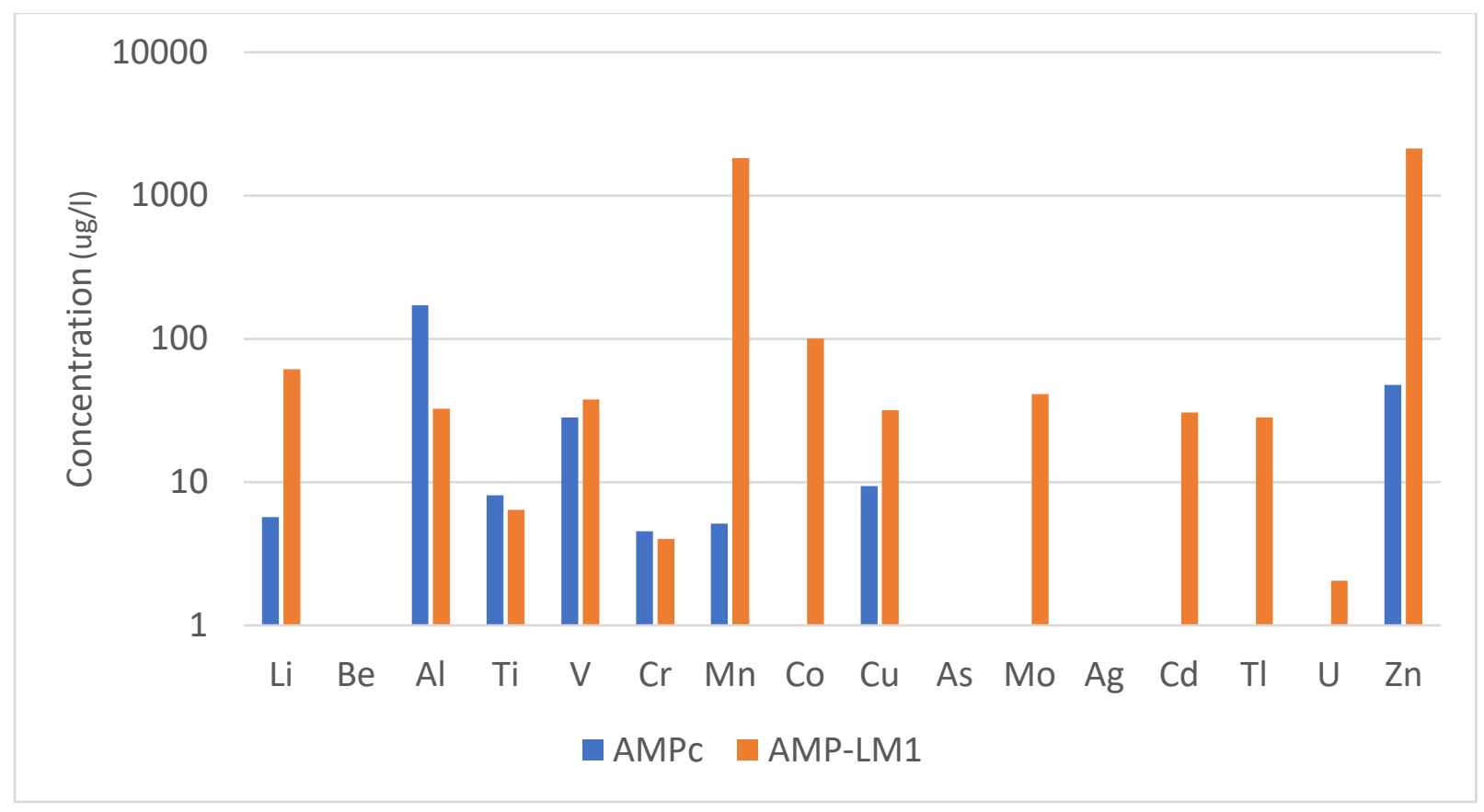

Figure 4: Critical minerals concentrations (AMPc and AMP-LM1). Analytes with concentrations <1ug/l were removed (Table S4).

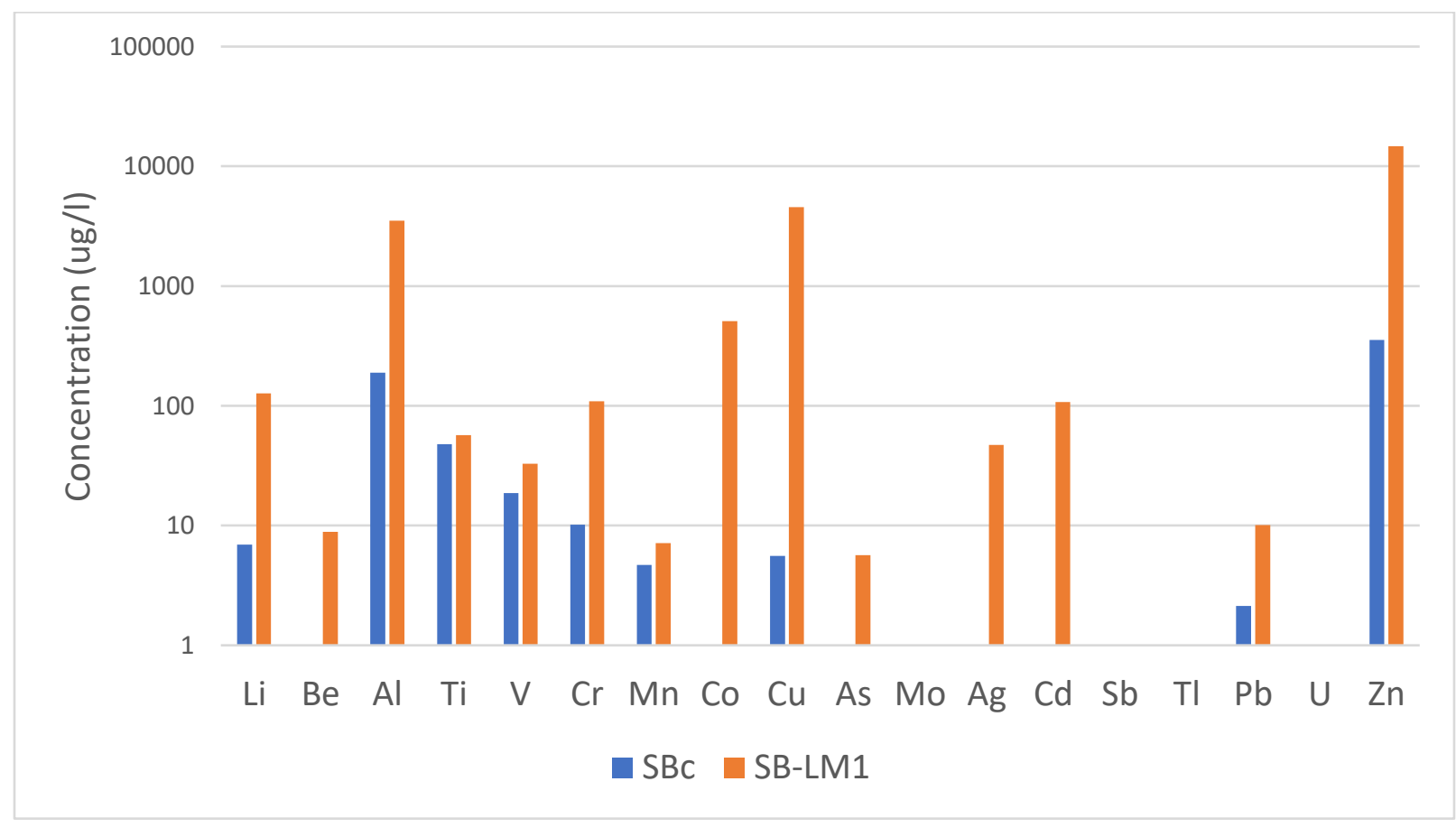

Figure 5: Critical mineral concentrations (SBc and SB-LM1). Analytes with concentrations <1 ug/l were removed (Table S4). 


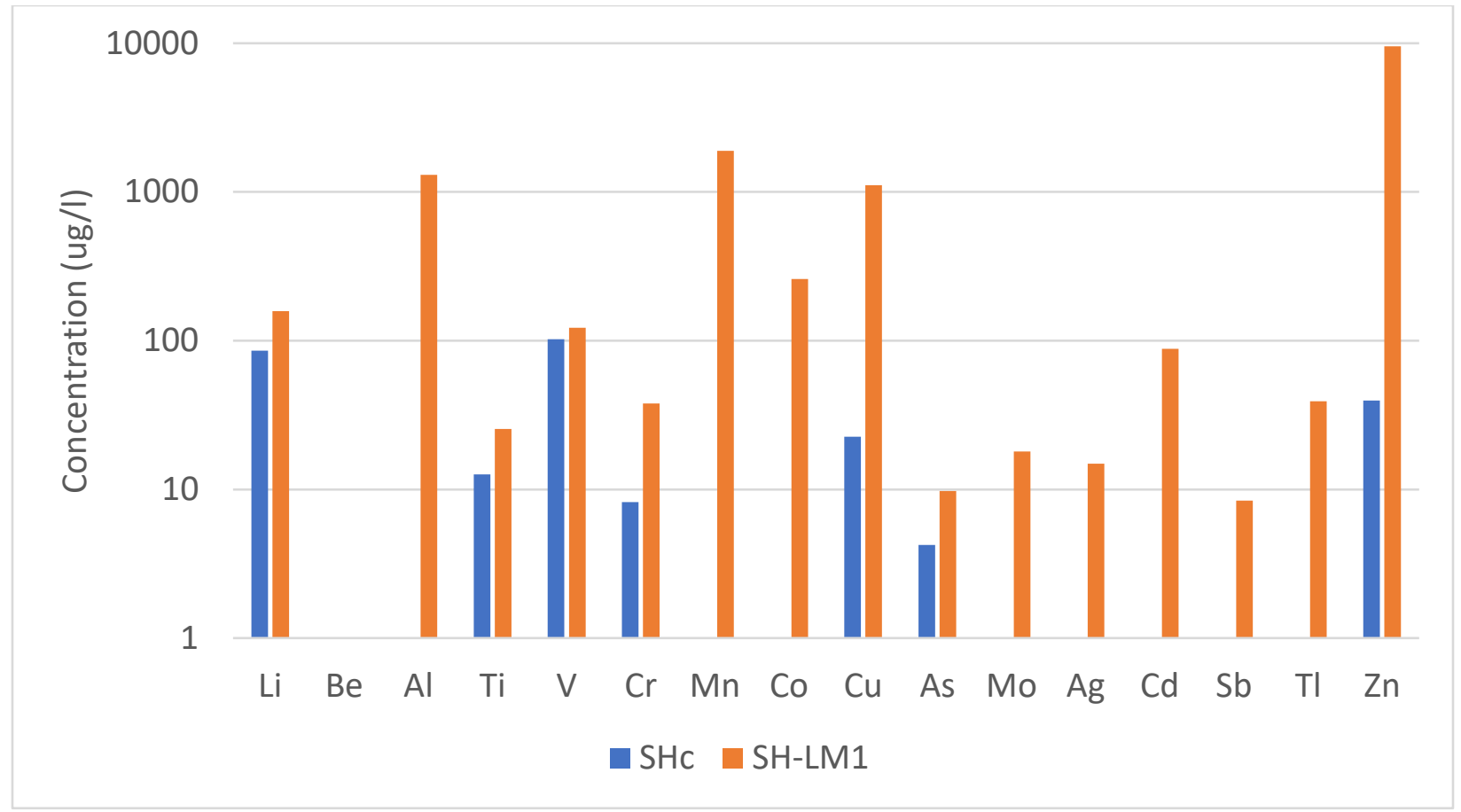

Figure 6: Critical mineral concentrations (SHc and SH-LM1). Analytes with concentrations $<1$ ug/l were removed (Table $\mathbf{S 4}$ ).

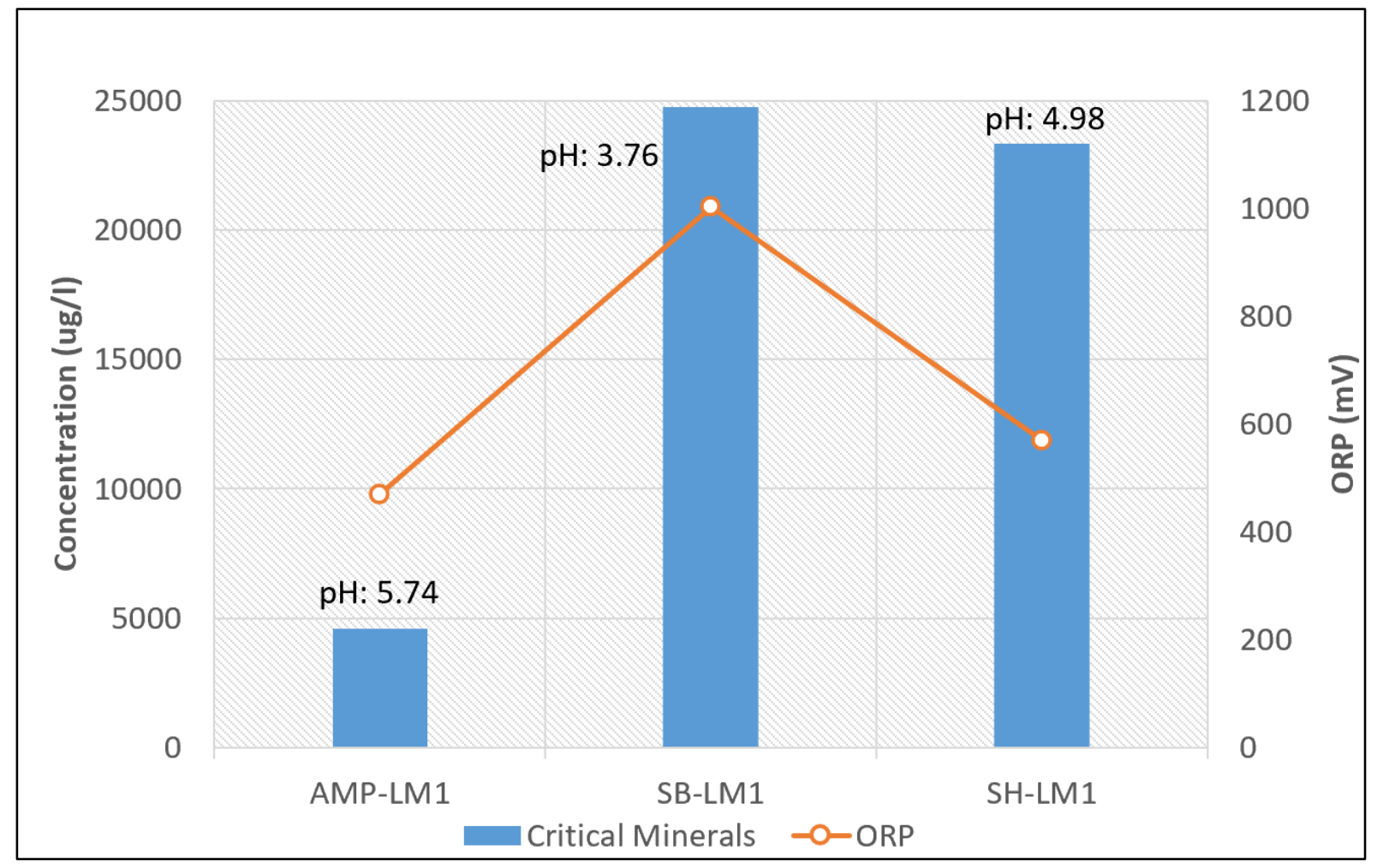

Figure 7: Critical mineral concentrations in shale reacted effluents and the initial ORP of HFF before analysis. Notice a higher ORP with higher critical mineral concentrations. 


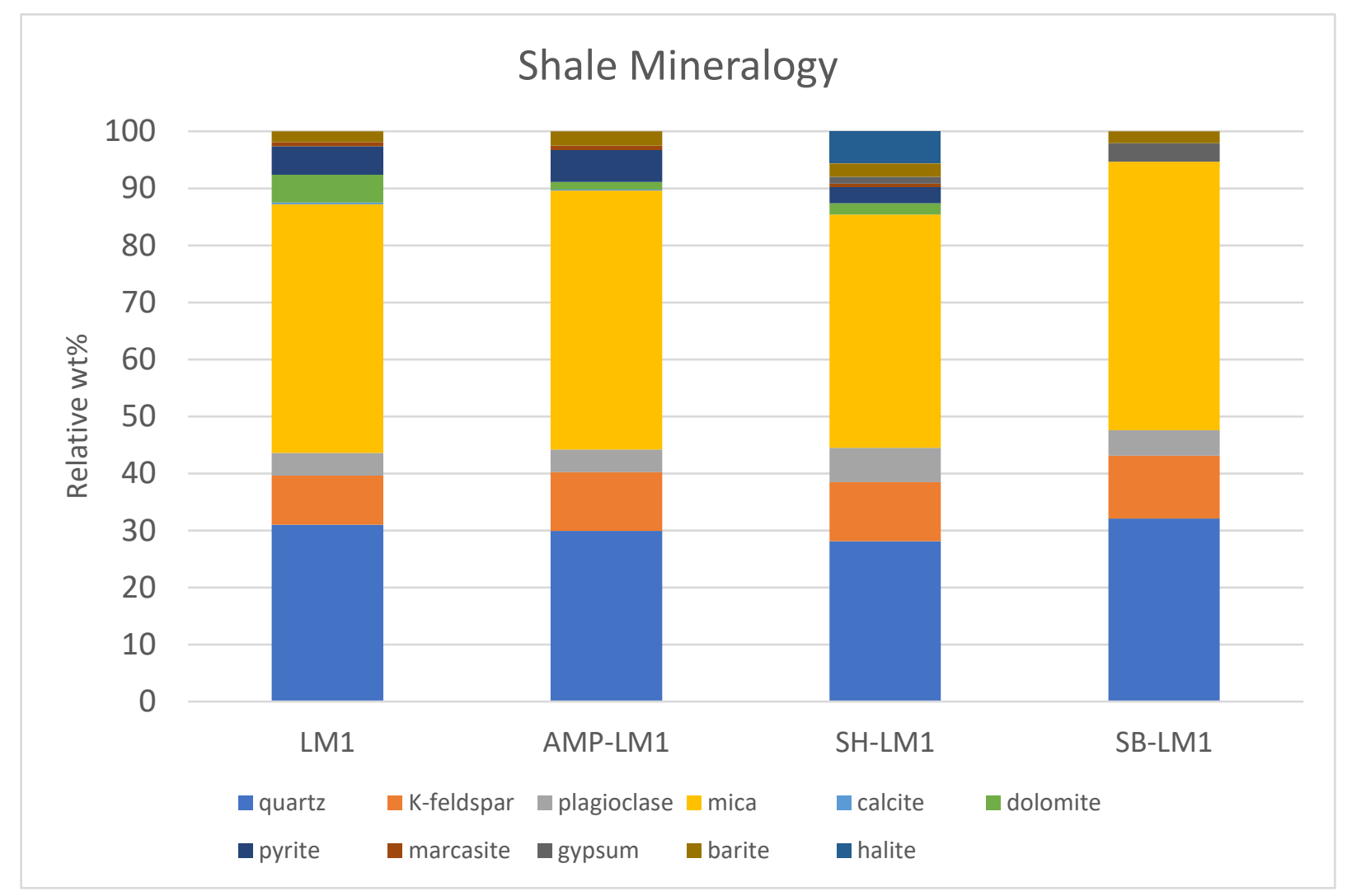

Figure 8: XRD results showing the original mineral composition of LM1 and the composition of LM1 after reaction with the oxidative HFF's. Values were measured within reporting limit standards of $<5 \%$. 


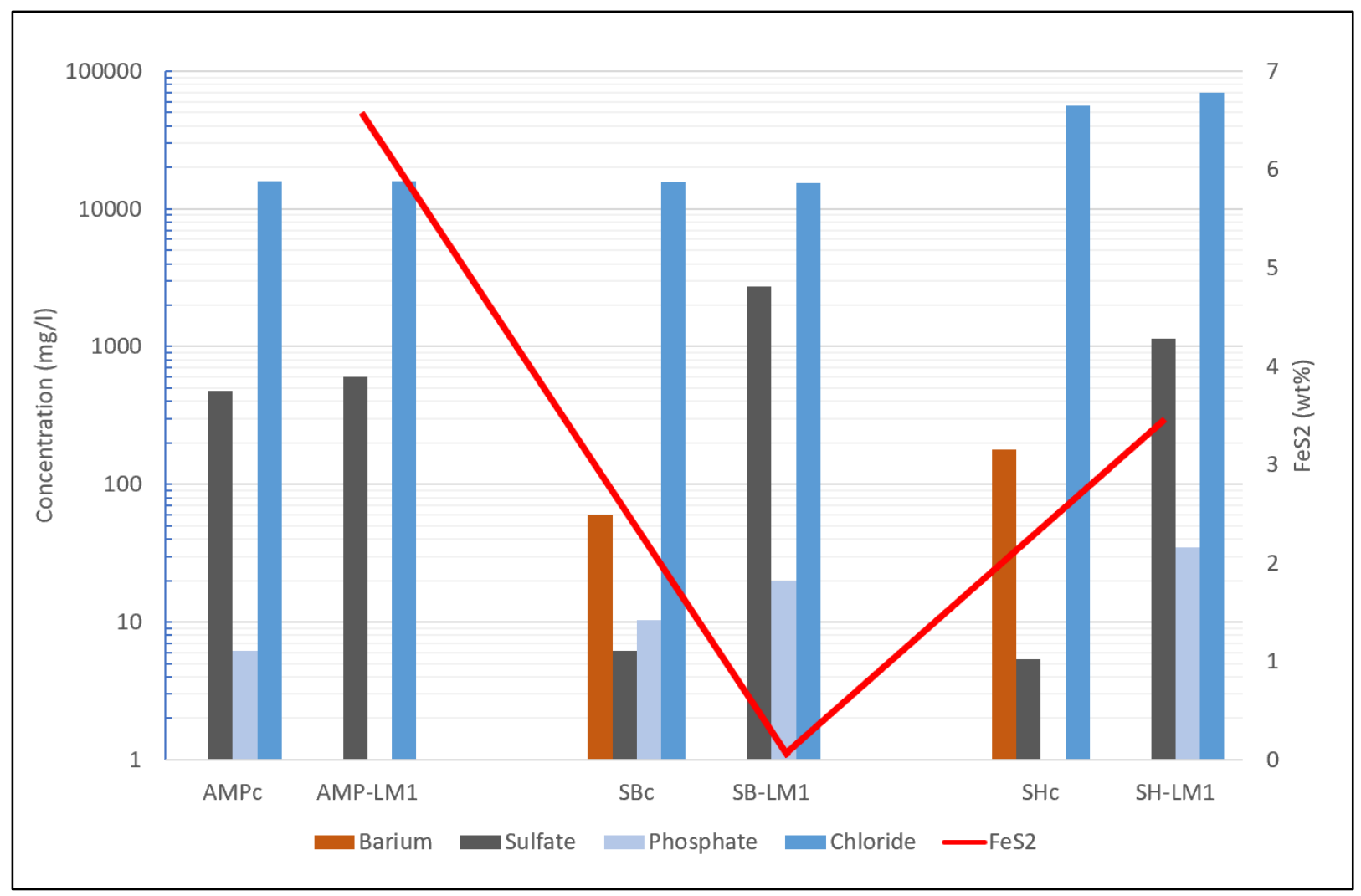

Figure 9: Concentrations of barium, sulfate, phosphate, and chloride in control and shale reacted effluents. An increase in sulfate concentration can be associated in samples where $\mathrm{FeS}_{2}$ was consumed to the greatest extent. 


\subsection{Supplementary Information:}

Table S1: Volatile organic compounds observed in the control fluids. Results and MDL are reported in ug/l. *ND - Not Detected

\begin{tabular}{|c|c|c|c|c|c|c|}
\hline Analyte & AMPC & MDL & $\mathbf{S B} \mathbf{B}_{\mathbf{C}}$ & MDL & $\mathrm{SHC}_{\mathrm{C}}$ & MDL \\
\hline Acetone & 100000 & 2820 & 1610 & 282 & 451 & 11.3 \\
\hline Acrolein & ND & - & ND & - & ND & - \\
\hline Acrylonitrile & ND & - & ND & - & ND & - \\
\hline Benzene & 0.172 & 0.0941 & ND & - & ND & - \\
\hline Bromobenzene & ND & - & ND & - & 1.31 & 0.118 \\
\hline Bromochloromethane & ND & - & 64.5 & 3.2 & ND & - \\
\hline Bromodichloromethane & 1.39 & 0.136 & 175 & 3.4 & 2030 & 34 \\
\hline Bromoform & 5.28 & 0.129 & 91800 & 258 & 478 & 32.3 \\
\hline Bromomethane & ND & - & 15.3 & 15.1 & 25.1 & 0.605 \\
\hline n-Butylbenzene & ND & - & ND & - & ND & - \\
\hline sec-Butylbenzene & ND & - & ND & - & ND & - \\
\hline tert-Butylbenzene & ND & - & ND & - & ND & - \\
\hline Carbon disulfide & 1.55 & 0.0962 & 274 & 2.41 & 66.2 & 0.0962 \\
\hline Carbon tetrachloride & ND & - & ND & - & 31.7 & 0.128 \\
\hline Chlorobenzene & ND & - & ND & - & 0.161 & 0.116 \\
\hline Chlorodibromomethane & 2.04 & 0.14 & 2070 & 3.5 & 957 & 35 \\
\hline Chloroethane & & & 39.8 & 4.8 & 7.91 & 0.192 \\
\hline Chloroform & 0.857 & 0.111 & 88.7 & 2.78 & 10900 & 27.8 \\
\hline Chloromethane & ND & - & ND & - & 616 & 240 \\
\hline 2-Chlorotoluene & ND & - & ND & - & ND & - \\
\hline 4-Chlorotoluene & ND & - & ND & - & ND & - \\
\hline $\begin{array}{l}\text { 1,2-Dibromo-3- } \\
\text { Chloropropane }\end{array}$ & ND & - & ND & - & 1.82 & 0.276 \\
\hline 1,2-Dibromoethane & ND & - & ND & - & ND & - \\
\hline Dibromomethane & ND & - & 74.4 & 3.05 & 10.3 & 0.122 \\
\hline 1,2-Dichlorobenzene & ND & - & ND & - & 0.136 & 0.107 \\
\hline 1,3-Dichlorobenzene & ND & - & ND & - & ND & - \\
\hline 1,4-Dichlorobenzene & ND & - & ND & - & ND & - \\
\hline Dichlorodifluoromethane & ND & - & ND & - & ND & - \\
\hline 1,1-Dichloroethane & ND & - & ND & - & 2.61 & 0.1 \\
\hline 1,2-Dichloroethane & ND & - & ND & - & 1.43 & 0.0819 \\
\hline 1,1-Dichloroethene & ND & - & ND & - & ND & - \\
\hline cis-1,2-Dichloroethene & ND & - & ND & - & ND & - \\
\hline trans-1,2-Dichloroethene & ND & - & ND & - & ND & - \\
\hline trans-1,4-Dichloro-2-butene & ND & - & ND & - & ND & - \\
\hline 1,2-Dichloropropane & ND & - & ND & - & ND & - \\
\hline 1,1-Dichloropropene & ND & - & ND & - & ND & - \\
\hline
\end{tabular}




\begin{tabular}{|c|c|c|c|c|c|c|}
\hline 1,3-Dichloropropane & ND & - & 3.55 & 2.75 & 0.538 & 0.11 \\
\hline cis-1,3-Dichloropropene & ND & - & ND & - & ND & - \\
\hline trans-1,3-Dichloropropene & ND & - & ND & - & ND & - \\
\hline 2,2-Dichloropropane & ND & - & ND & - & ND & - \\
\hline Di-isopropyl ether & ND & - & ND & - & ND & - \\
\hline Ethylbenzene & ND & - & ND & - & ND & - \\
\hline Hexachloro-1,3-butadiene & ND & - & ND & - & ND & - \\
\hline 2-Hexanone & ND & - & 41.7 & 19.7 & 2.87 & 0.787 \\
\hline Iodomethane & ND & - & ND & - & 150 & 6 \\
\hline Isopropylbenzene & ND & - & ND & - & ND & - \\
\hline p-Isopropyltoluene & ND & - & ND & - & ND & - \\
\hline 2-Butanone(MEK) & 3.65 & 1.19 & 244 & 29.8 & 32.2 & 1.19 \\
\hline Methylene Chloride & ND & - & 50.2 & 10.7 & 24.1 & 0.43 \\
\hline $\begin{array}{c}\text { 4-Methyl-2-pentanone } \\
\text { (MIBK) }\end{array}$ & ND & - & ND & - & ND & - \\
\hline Methyl tert-butyl ether & 0.57 & 0.101 & ND & - & 0.267 & 0.101 \\
\hline Napthalene & ND & - & ND & - & ND & - \\
\hline n-Propylbenzene & ND & - & ND & - & ND & - \\
\hline Styrene & ND & - & ND & - & ND & - \\
\hline 1,1,1,2-Tetrachloroethane & ND & - & ND & - & ND & - \\
\hline 1,1,2,2-Tetrachloroethane & ND & - & ND & - & ND & - \\
\hline 1,1,2-Trichlorotrifluoroethane & ND & - & ND & - & ND & - \\
\hline Tetrachloroethene & ND & - & ND & - & ND & - \\
\hline Toluene & ND & - & ND & - & ND & - \\
\hline 1,2,3-Trichlorobenzene & ND & - & ND & - & ND & - \\
\hline 1,2,4-Trichlorobenzene & ND & - & ND & - & ND & - \\
\hline 1,1,1-Trichloroethane & ND & - & ND & - & ND & - \\
\hline 1,1,2-Trichloroethane & ND & - & ND & - & $\mathrm{ND}$ & - \\
\hline Trichloroethene (TCE) & ND & - & ND & - & ND & - \\
\hline Trichlorofluoromethane & ND & - & ND & - & ND & - \\
\hline 1,2,3-Trichloropropane & ND & - & $\mathrm{ND}$ & - & 8.67 & 0.237 \\
\hline 1,2,4-Trimethylbenzene & ND & - & ND & - & $\mathrm{ND}$ & - \\
\hline 1,2,3-Trimetylbenzene & 4.81 & 0.104 & ND & - & ND & - \\
\hline 1,3,5-Trimethylbenzene & ND & - & ND & - & ND & - \\
\hline Vinyl acetate & ND & - & ND & - & ND & - \\
\hline Vinyl chloride & ND & - & ND & - & ND & - \\
\hline o-Xylene & ND & - & ND & - & ND & - \\
\hline m\&p-Xylene & ND & - & ND & - & ND & - \\
\hline
\end{tabular}


Table S2: Volatile organic compounds observed in shale reacted effluents. Results and MDL are reported in ug/L. *ND - Not Detected

\begin{tabular}{|c|c|c|c|c|c|c|}
\hline Analyte & AMP-LM1 & MDL & SB-LM1 & MDL & SH-LM1 & MDL \\
\hline Acetone & 7630 & 113 & 1660 & 565 & 1670 & 56.5 \\
\hline Acrolein & ND & - & ND & - & $\mathrm{ND}$ & - \\
\hline Acrylonitrile & ND & - & ND & - & ND & - \\
\hline Benzene & 1.35 & 0.094 & 8.86 & 5.9 & 9.14 & 0.471 \\
\hline Bromobenzene & ND & - & 71.3 & 6.4 & ND & - \\
\hline Bromochloromethane & 0.332 & 0.128 & 3910 & 6.8 & ND & - \\
\hline Bromodichloromethane & ND & - & 97600 & 322 & 9890 & 340 \\
\hline Bromoform & $\mathrm{ND}$ & - & 36.1 & 30.3 & 9110 & 322 \\
\hline Bromomethane & ND & - & ND & - & ND & - \\
\hline n-Butylbenzene & ND & - & ND & - & ND & - \\
\hline sec-Butylbenzene & ND & - & ND & - & ND & - \\
\hline tert-Butylbenzene & ND & - & ND & - & ND & - \\
\hline Carbon disulfide & 14.7 & 0.0962 & 1290 & 4.81 & 147 & 0.481 \\
\hline Carbon tetrachloride & ND & - & ND & - & 201 & 0.64 \\
\hline Chlorobenzene & ND & - & ND & - & ND & - \\
\hline Chlorodibromomethane & ND & - & 16400 & 350 & 13200 & 350 \\
\hline Chloroethane & 0.407 & 0.192 & 42.8 & 9.6 & 43.7 & 0.96 \\
\hline Chloroform & 0.333 & 0.111 & 100 & 5.55 & ND & - \\
\hline Chloromethane & ND & - & ND & - & 228 & 4.8 \\
\hline 2-Chlorotoluene & $\mathrm{ND}$ & - & ND & - & 10.7 & 0.53 \\
\hline 4-Chlorotoluene & $\mathrm{ND}$ & - & ND & - & 5.29 & 0.57 \\
\hline $\begin{array}{l}\text { 1,2-Dibromo-3- } \\
\text { Chloropropane }\end{array}$ & ND & - & ND & - & ND & - \\
\hline 1,2-Dibromoethane & ND & - & ND & - & ND & - \\
\hline Dibromomethane & ND & - & 164 & 6.1 & 57.1 & 0.61 \\
\hline 1,2-Dichlorobenzene & ND & - & ND & - & ND & - \\
\hline 1,3-Dichlorobenzene & ND & - & ND & - & ND & - \\
\hline 1,4-Dichlorobenzene & ND & - & ND & - & 2.75 & 0.6 \\
\hline Dichlorodifluoromethane & ND & - & ND & - & ND & - \\
\hline 1,1-Dichloroethane & ND & - & ND & - & 17.8 & 0.5 \\
\hline 1,2-Dichloroethane & 3.42 & 0.0819 & ND & - & ND & - \\
\hline 1,1-Dichloroethene & ND & - & ND & - & 14.7 & 0.94 \\
\hline cis-1,2-Dichloroethene & ND & - & ND & - & 1.13 & 0.63 \\
\hline trans-1,2-Dichloroethene & ND & - & ND & - & ND & - \\
\hline trans-1,4-Dichloro-2-butene & ND & - & ND & - & ND & - \\
\hline 1,2-Dichloropropane & ND & - & ND & - & ND & - \\
\hline 1,1-Dichloropropene & ND & - & ND & - & ND & - \\
\hline 1,3-Dichloropropane & ND & - & ND & - & 0.963 & 0.55 \\
\hline cis-1,3-Dichloropropene & ND & - & $\mathrm{ND}$ & - & $\mathrm{ND}$ & - \\
\hline trans-1,3-Dichloropropene & ND & - & ND & - & ND & - \\
\hline
\end{tabular}




\begin{tabular}{|c|c|c|c|c|c|c|}
\hline 2,2-Dichloropropane & ND & - & ND & - & ND & - \\
\hline Di-isopropyl ether & ND & - & ND & - & ND & - \\
\hline Ethylbenzene & 0.745 & 0.137 & ND & - & 6.27 & 0.685 \\
\hline Hexachloro-1,3-butadiene & ND & - & ND & - & ND & - \\
\hline 2-Hexanone & ND & - & ND & - & 15.3 & 3.94 \\
\hline Iodomethane & ND & - & ND & - & 35.6 & 30 \\
\hline Isopropylbenzene & ND & - & ND & - & 0.857 & 0.525 \\
\hline p-Isopropyltoluene & ND & - & ND & - & ND & - \\
\hline 2-Butanone(MEK) & 15.2 & 1.19 & 282 & 59.5 & 148 & 5.95 \\
\hline Methylene Chloride & 201 & 4.3 & 257 & 21.5 & 181 & 2.15 \\
\hline $\begin{array}{l}\text { 4-Methyl-2-pentanone } \\
\text { (MIBK) }\end{array}$ & 0.658 & 0.478 & ND & - & ND & - \\
\hline Methyl tert-butyl ether & 0.713 & 0.1 & ND & - & 0.632 & 0.505 \\
\hline Napthalene & ND & - & ND & - & ND & - \\
\hline n-Propylbenzene & ND & - & ND & - & 0.677 & 0.497 \\
\hline Styrene & ND & - & ND & - & ND & - \\
\hline 1,1,1,2-Tetrachloroethane & ND & - & ND & - & ND & - \\
\hline 1,1,2,2-Tetrachloroethane & ND & - & ND & - & ND & - \\
\hline $\begin{array}{c}1,1,2- \\
\text { Trichlorotrifluoroethane }\end{array}$ & ND & - & ND & - & ND & - \\
\hline Tetrachloroethene & ND & - & ND & - & ND & - \\
\hline Toluene & 8.92 & 0.278 & ND & - & 39 & 1.39 \\
\hline 1,2,3-Trichlorobenzene & ND & - & ND & - & ND & - \\
\hline 1,2,4-Trichlorobenzene & ND & - & ND & - & ND & - \\
\hline 1,1,1-Trichloroethane & ND & - & ND & - & 10.6 & 0.745 \\
\hline 1,1,2-Trichloroethane & ND & - & ND & - & ND & - \\
\hline Trichloroethene (TCE) & ND & - & ND & - & 10.7 & 0.95 \\
\hline Trichlorofluoromethane & ND & - & ND & - & ND & - \\
\hline 1,2,3-Trichloropropane & ND & - & ND & - & ND & - \\
\hline 1,2,4-Trimethylbenzene & ND & - & ND & - & ND & - \\
\hline 1,2,3-Trimetylbenzene & ND & - & $\mathrm{ND}$ & - & ND & - \\
\hline 1,3,5-Trimethylbenzene & ND & - & ND & - & $\mathrm{ND}$ & - \\
\hline Vinyl acetate & ND & - & ND & - & ND & - \\
\hline Vinyl chloride & ND & - & ND & - & ND & - \\
\hline o-Xylene & 0.695 & 0.174 & ND & - & 5.71 & 0.87 \\
\hline m\&p-Xylene & 1.94 & 0.43 & ND & - & 7.8 & 2.15 \\
\hline
\end{tabular}


Table S3: Semi volatile organic compounds (PAHs) observed in effluents in this study. Results and MDL are reported in ug/L. *ND - Not Detected

\begin{tabular}{|c|c|c|c|c|c|c|}
\hline Analyte & SBc & MDL & SHc & MDL & AMP-LM1 & MDL \\
\hline Anthracene & ND & - & ND & - & ND & - \\
\hline Acenapthene & ND & - & ND & - & ND & - \\
\hline Acenaphthylene & ND & - & ND & - & ND & - \\
\hline Benzo(a)anthracene & ND & - & ND & - & ND & - \\
\hline Benzo(a)pyrene & ND & - & ND & - & ND & - \\
\hline Benzo(b)fluoranthene & ND & - & ND & - & ND & - \\
\hline Benzo(g,h,i)perylene & ND & - & ND & - & ND & - \\
\hline Benzo(k)fluoranthene & ND & - & ND & - & ND & - \\
\hline Chrysene & ND & - & ND & - & 0.0252 & 0.018 \\
\hline Dibenz(a,h)anthracene & ND & - & ND & - & ND & - \\
\hline Fluoranthene & ND & - & ND & - & 0.0141 & 0.011 \\
\hline Fluorene & ND & - & ND & - & ND & - \\
\hline Indeno(1,2,3-cd)pyrene & ND & - & ND & - & ND & - \\
\hline Napthalene & ND & - & ND & - & ND & - \\
\hline Phenanthrene & ND & - & ND & - & ND & - \\
\hline Pyrene & ND & - & ND & - & ND & - \\
\hline 1-Methylnapthalene & 0.0265 & 0.02 & 0.0311 & 0.02 & ND & - \\
\hline 2-Methylnapthalene & ND & - & ND & - & ND & - \\
\hline 2-Chloronaphthalene & ND & - & ND & - & ND & - \\
\hline
\end{tabular}


Table S4: Critical minerals (metals and metalloids) measured from ICP-MS and ICP-OES analysis.

\begin{tabular}{|c|c|c|c|c|c|c|}
\hline ICP-MS & AMP-LM1 & SB-LM1 & SH-LM1 & AMPc & SBc & SHc \\
\hline Analyte & ug/L & ug/L & ug/L & ug/L & ug/L & ug/L \\
\hline $\mathrm{Li}$ & 61.5 & 127 & 158 & 5.69 & 6.93 & 85.8 \\
\hline $\mathrm{Be}$ & $<\mathrm{DL}$ & 8.88 & $<\mathrm{DL}$ & $<\mathrm{DL}$ & $<\mathrm{DL}$ & $<\mathrm{DL}$ \\
\hline $\mathrm{B}$ & 4672 & 5919 & 5649 & 4110 & 3726 & 4688 \\
\hline $\mathrm{Mg}$ & 356861 & 462765 & 146709 & 254086 & 255762 & 179009 \\
\hline $\mathrm{Al}$ & 32.5 & 3517 & 1301 & 171 & 188 & $<\mathrm{DL}$ \\
\hline $\mathrm{Si}$ & 21197 & 37717 & 30989 & 4996 & 6525 & 12813 \\
\hline $\mathrm{K}$ & 359965 & 359335 & 368737 & 368730 & 369468 & 380635 \\
\hline $\mathrm{Ti}$ & 6.41 & 56.8 & 25.4 & 8.08 & 47.7 & 12.6 \\
\hline $\mathrm{V}$ & 37.8 & 32.8 & 122 & 28.3 & 18.7 & 102 \\
\hline $\mathrm{Cr}$ & 4.01 & 109 & 37.8 & 4.53 & 10.2 & 8.21 \\
\hline $\mathrm{Mn}$ & 1830 & 7.14 & 1890 & 5.12 & 4.69 & $<\mathrm{DL}$ \\
\hline $\mathrm{Fe}$ & 252 & 185 & 8493 & 302 & 191 & 125 \\
\hline $\mathrm{Co}$ & 100 & 511 & 259 & $<\mathrm{DL}$ & $<\mathrm{DL}$ & $<\mathrm{DL}$ \\
\hline $\mathrm{Cu}$ & 31.8 & 4571 & 1112 & 9.36 & 5.58 & 22.6 \\
\hline $\mathrm{As}$ & $<\mathrm{DL}$ & 5.67 & 9.73 & $<\mathrm{DL}$ & $<\mathrm{DL}$ & 4.23 \\
\hline $\mathrm{Se}$ & $<\mathrm{DL}$ & 725 & 181 & $<\mathrm{DL}$ & 356 & 77.0 \\
\hline $\mathrm{Mo}$ & 41.0 & $<\mathrm{DL}$ & 18.0 & $<\mathrm{DL}$ & $<\mathrm{DL}$ & $<\mathrm{DL}$ \\
\hline $\mathrm{Ag}$ & $<\mathrm{DL}$ & 47.3 & 14.9 & $<\mathrm{DL}$ & $<\mathrm{DL}$ & $<\mathrm{DL}$ \\
\hline $\mathrm{Cd}$ & 30.6 & 107 & 88.2 & $<\mathrm{DL}$ & $<\mathrm{DL}$ & $<\mathrm{DL}$ \\
\hline $\mathrm{Sb}$ & 0.08 & $<\mathrm{DL}$ & 8.39 & $<\mathrm{DL}$ & $<\mathrm{DL}$ & $<\mathrm{DL}$ \\
\hline $\mathrm{Tl}$ & 28.3 & $<\mathrm{DL}$ & 39.1 & $<\mathrm{DL}$ & $<\mathrm{DL}$ & $<\mathrm{DL}$ \\
\hline $\mathrm{Pb}$ & 0.587 & 10.1 & 29.5 & 7.22 & 2.13 & 0.819 \\
\hline $\mathrm{Th}$ & $<\mathrm{DL}$ & $<\mathrm{DL}$ & $<\mathrm{DL}$ & $<\mathrm{DL}$ & $<\mathrm{DL}$ & $<\mathrm{DL}$ \\
\hline $\mathrm{U}$ & 2.05 & $<\mathrm{DL}$ & 0.567 & $<\mathrm{DL}$ & $<\mathrm{DL}$ & $<\mathrm{DL}$ \\
\hline $\mathrm{ICP}-\mathrm{OES}$ & $\mathrm{AMP}-\mathrm{LM} 1$ & $\mathrm{SB}-\mathrm{LM} 1$ & $\mathrm{SH}-\mathrm{LM} 1$ & $\mathrm{AMPc}$ & $\mathrm{SBc}$ & $\mathrm{SHc}$ \\
\hline $\mathrm{Analyte}$ & $\mathrm{ug} / \mathrm{L}$ & $\mathrm{ug} / \mathrm{L}$ & $\mathrm{ug} / \mathrm{L}$ & $\mathrm{ug} / \mathrm{L}$ & $\mathrm{ug} / \mathrm{L}$ & $\mathrm{ug} / \mathrm{L}$ \\
\hline $\mathrm{Ba}$ & 246 & $\mathrm{BDL}$ & 2098 & 179 & 67536 & 237096 \\
\hline $\mathrm{Ca}$ & 2352903 & 2355903 & 2076903 & 2176903 & 2111903 & 1460903 \\
\hline $\mathrm{Na}$ & 7456680 & 14128680 & 34698680 & 7631680 & 13708680 & 36668680 \\
\hline $\mathrm{Sr}$ & 192798 & 77658 & 380298 & 369298 & 473598 & 465398 \\
\hline $\mathrm{Zn}$ & 2131 & 14730 & 9554 & 48 & 354 & 40 \\
\hline & & & & & & \\
\hline
\end{tabular}

